\title{
A Regime-Based Evaluation of TRMM Oceanic Precipitation Biases
}

\author{
DAVID S. HENDERSON AND CHRISTIAN D. KUMMEROW \\ Department of Atmospheric Science, Colorado State University, Fort Collins, Colorado \\ DAVID A. MARKS \\ NASA Wallops Flight Facility, Wallops Island, Virginia, and Science Systems and Applications, Inc., Lanham, Maryland \\ WESLEY BERG \\ Department of Atmospheric Science, Colorado State University, Fort Collins, Colorado
}

(Manuscript received 16 December 2016, in final form 3 August 2017)

\begin{abstract}
Over the tropical oceans, large discrepancies in TRMM passive and active microwave rainfall retrievals become apparent during El Niño-Southern Oscillation (ENSO) events. This manuscript describes the application of defined precipitation regimes to aid the validation of instantaneous rain rates from TRMM using the S-band radar located on the Kwajalein Atoll. Through the evaluation of multiple case studies, biases in rain-rate estimates from the TRMM radar (PR) and radiometer (TMI) are best explained when derived as a function of precipitation organization (e.g., isolated vs organized) and precipitation type (convective vs stratiform). When examining biases at a $1^{\circ} \times 1^{\circ}$ scale, large underestimates in both TMI and PR rain rates are associated with predominately convective events in deep isolated regimes, where TMI and PR retrievals are underestimated by $37.8 \%$ and $23.4 \%$, respectively. Further, a positive bias of $33.4 \%$ is observed in TMI rain rates within organized convective systems containing large stratiform regions. These findings were found to be consistent using additional analysis from the DYNAMO field campaign. When validating at the TMI footprint scale, TMI-PR differences are driven by stratiform rainfall variability in organized regimes; TMI overestimates this stratiform precipitation by $92.3 \%$. Discrepancies between TMI and PR during El Niño events are related to a shift toward more organized convective systems and derived TRMM rain-rate bias estimates are able to explain 70\% of TMI-PR differences during El Niño periods. An extension of the results to passive microwave retrievals reveals issues in discriminating convective and stratiform rainfall within the TMI field of view (FOV), and significant reductions in bias are found when convective fraction is constrained within the Bayesian retrieval.
\end{abstract}

\section{Introduction}

Oceanic precipitation in the tropics accounts for nearly two-thirds of Earth's total precipitation and is a driving force in the variability in Earth's weather, climate, water cycle, and energy budget. The most profound interannual variability in tropical oceanic precipitation occurs with El Niño-Southern Oscillation (ENSO), where anomalies in equatorial Pacific sea surface temperatures (SST) influence variations in the structure of atmospheric wind, temperature, and moisture. These variations bring about changes in the cloud distribution and regional precipitation

Corresponding author: David Henderson, henderson@atmos. colostate.edu throughout the tropical oceans (Alexander et al. 2002; Held and Soden 2006; Su and Jiang 2013). In the current state, we depend on satellite observations to study these anomalies in oceanic precipitation because of the scarcity of reliable observations at the surface. The Tropical Rainfall Measuring Mission (TRMM; Kummerow et al. 1998) satellite provided consistent quantification of the evolving rainfall field for 16 years-dating from 1998 through 2014. The TRMM mission revolutionized precipitation remote sensing by complementing the TRMM Microwave Imager (TMI) with the TRMM Precipitation Radar (PR) - the first spaceborne precipitation radar.

Variations in regional precipitation characteristics have been observed using TMI and PR data during various ENSO events (e.g., Schumacher and Houze 

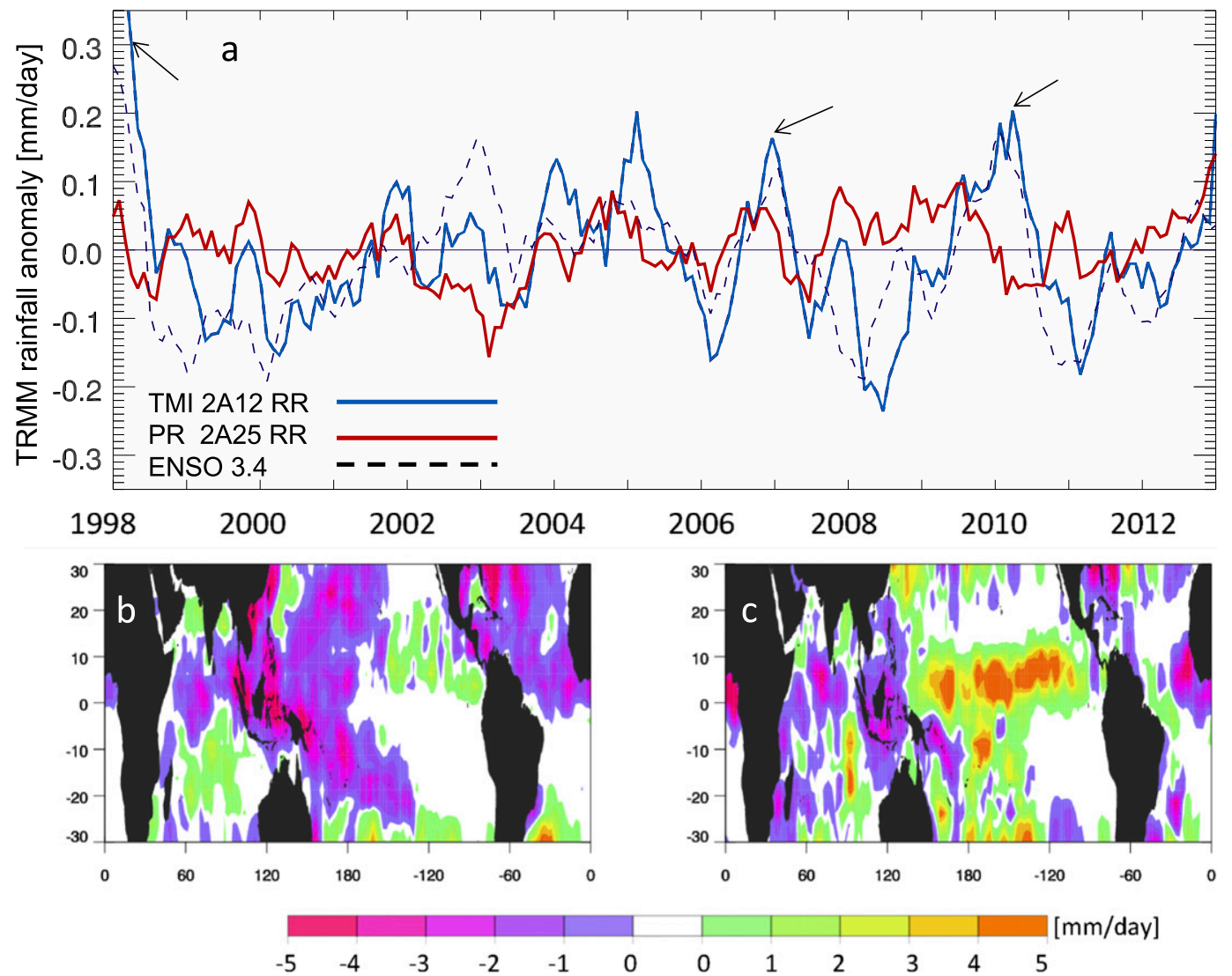

FIG. 1. (a) Time series of tropical mean rainfall anomalies $\left(30^{\circ} \mathrm{N}-30^{\circ} \mathrm{S}\right)$ from the TRMM PR $2 \mathrm{~A} 25$ (red) and TMI 2A12 (blue) over the tropical oceans. Three isolated El Niño events $(1998,2007$, and 2010) are highlighted with arrows. (b) TMI-PR differences for a 3-month mean for December 2008, January 2009, and February 2009. (c) TMI-PR differences for a 3-month mean for December 2009, January 2010, and February 2010.

2000, 2003; Masunaga et al. 2005; Berg et al. 2002). These perturbations in precipitation are not in agreement between TMI and PR, where the differences in tropics-wide TRMM rain-rate anomalies associated with ENSO variability are found to be driven by precipitation occurring over the tropical oceans (e.g., Adler et al. 2009; Wang et al. 2008). Figure 1a displays TMI and PR oceanic precipitation anomalies occurring throughout the TRMM mission. Time-dependent discrepancies between the TMI and PR rain-rate anomalies are visible between the varying phases of ENSO, where TMI rain rates exhibit variability correlated with the ENSO-3.4 index but PR does not. As an example, differences between TMI and PR are observed during isolated El Niño events in 1998, 2007, and 2010; these events contributed to a notable increase in oceanic precipitation anomalies from passive microwave rain estimates, whereas the active PR rainfall remains nearly constant. The opposite occurs during La Niña periods, when TMI rain rates are generally underestimated compared to PR.
The discrepancies occurring between the TRMM precipitation products are driven by systematic shifts in regional biases (Figs. 1b,c). For example, during the 2008/09 La Niña event (Fig. 1b), large underestimates in TMI rainfall compared to PR are readily observed. During the peak of the 2009/10 El Niño, changes in the mean precipitation state drive differences toward an overestimation of TMI rain rates within a large region located in the central and western Pacific (Fig. 1c). Because the TMI and PR retrievals rely on different physics when retrieving rain rates, situation-dependent biases found between the products have been related to differences in regional cloud microphysics and variations in large-scale environmental properties (Berg et al. 2002, 2006; Masunaga and Kummerow 2005). To understand retrieval accuracy, however, it is beneficial to collocate TRMM estimates with an independent validation source to estimate satellite retrieval error (Wolff and Fisher 2008, 2009; Kirstetter et al. 2012).

Previous studies have characterized the associated differences between the TMI and PR precipitation 
retrievals as related to larger-scale environmental features or precipitation microphysics (e.g., Berg et al. 2002, 2006; Nesbitt et al. 2004; Shige et al. 2006, 2008; Adler et al. 2012; Seo et al. 2007, 2015). To grasp the magnitude of the difference between the satellite products while also understanding which products produce an accurate retrieval, an independent source of rainfall estimates such as described in the TRMM-GPM ground validation (GV) program (Wolff et al. 2005) becomes necessary.

The GV network located on the Kwajalein Atoll provides the opportunity to advance our knowledge of oceanic precipitation uncertainty (e.g., Schumacher and Houze 2003; Wolff and Fisher 2008, 2009; Bringi et al. 2012; Munchak et al. 2012). While the above-referenced studies have aided the validation of random and systematic errors occurring in TRMM instantaneous rainrate estimates, there is still lack of a thorough assessment of the PR and TMI retrievals in relation to situationdependent biases that occur with ENSO-induced variability. Wolff and Fisher (2008) demonstrated that annual biases between TRMM rain rates and GV will vary from year to year. Based upon the regional differences in Fig. 1, it can be hypothesized that the mean cloud state is substantially different between the ENSO phases. If TRMM biases relate to changes in precipitation properties, then it might be beneficial to focus validation on distinct precipitating systems that represent TRMM rain-rate biases consistently throughout space and time.

To ensure representation of the diverse nature of convection within the tropics, recent work has begun to segregate precipitation events by large-scale features (e.g., Rasmussen et al. 2013; Liu and Zipser 2014; Seo et al. 2015; Petkovic and Kummerow 2016; Henderson et al. 2017). Further, Wang et al. (2008) discussed how increased information on the large-scale environment might be necessary to reconcile TMI and PR discrepancies related to ENSO. Elsaesser et al. (2010) describe such a methodology to classify the level of organization within a precipitating system through the use of a $k$-means clustering classification. The $k$-means clustering method classifies precipitation regimes based on a cloud's properties within $1^{\circ} \times 1^{\circ}$ boxes along the PR swath. These precipitating systems exhibit self-similar characteristics across the global oceans and thus were recommended for use in validation exercises because of their applicability across synoptic regions. By prompting such validation procedures, the contribution of defined convective systems to precipitation biases can be derived. Then by observing the changes in the occurrence of each precipitation regime, we can assess the impact of each precipitation regime on TRMM rainfall discrepancies over time.
To thoroughly comprehend the sources of regional biases between TMI and PR observed over the tropical oceans, we extend GV efforts to compare instantaneous TMI and PR rain rates as a function of their large-scale convective organization. This work looks to advance assessments of bias by providing bias estimates associated with individual convective systems using observations from the Kwajalein GV site and the Dynamics of the MJO (DYNAMO) field campaign The Kwajalein GV site and the DYNAMO campaign are ideal oceanic locations for examining TRMM biases because of their proximity to frequent and diverse convective systems. The DYNAMO field campaign has provided new insights into the multiscale processes during MJO initiation over the Indian Ocean This includes ground-radar-based datasets to observe the varying convective population and precipitating systems (e.g., Zuluaga and Houze 2013; Powell and Houze 2013), which can be used to check the consistency of results derived at the Kwajalein Atoll. The ground-based observations are then used to investigate precipitation retrievals to help understand how these validation results can propagate into retrieval development. Section 2 introduces the datasets used within this study and the methodology implemented to create the results. Section 3 presents the instantaneous comparisons of TMI and PR data segregated by individual precipitation regimes. Section 4 relates how understanding variability in the precipitation regimes could be used to describe the rain-rate discrepancies, and section 5 describes how the bias-related results could help aid the GPROF retrieval and where we can begin looking to improve biases inherent in the Bayesian process. Summary and conclusions are presented in section 6 .

\section{Data sources and methodology}

\section{a. TRMM-GPM GV products}

The Kwajalein GV site provides continuous radar information from the Kwajalein polarimetric (KPOL) dual-polarized S-band radar. Data from the KPOL site is used to validate TRMM observations from the period 2008-13. The period 2008-13 is chosen because it is documented to contain stable calibrated reflectivity data within $\pm 0.5 \mathrm{~dB}$ (Silberstein et al. 2008; Marks et al. 2009). To provide accurate rainfall observations, this work utilizes rain-rate measurements calculated by applying the methodology of Bringi et al. (2004) to the dual-polarized variables from the KPOL radar. The method utilizes horizontal reflectivity $Z_{\mathrm{H}}$, differential reflectivity $Z_{\mathrm{DR}}$, and the differential propagation $K_{\mathrm{DP}}$ phase to dynamically adjust the coefficient " $a$ " in the $Z-R$ relationship $Z=a R^{1.5}$ on a pixel-by-pixel basis, which results in noticeably improved correlations with rain gauges without 
the need for rain gauge calibration (Marks et al. 2009; Henderson et al. 2017). Convective and stratiform precipitation type separation for the KPOL radar rain rates are provided in version 7 of the TRMM GV 2A54 product, and the ground validation products are gridded in a Cartesian coordinate dataset with a horizontal resolution of $2 \mathrm{~km}$ and a vertical resolution of $750 \mathrm{~m}$.

\section{b. TRMM satellite products}

\section{1) TRMM PR $2 A 25$ PRODUCT}

The use of active precipitation radars, such as the TRMM PR, allows for observations of precipitation properties in three-dimensional space. In this work, data from the TRMM Precipitation Radar product, version $72 \mathrm{~A} 25$, provides surface rain-rate estimates and precipitation type partitioning. The three-dimensional observations available from the radar product provide pixel-by-pixel vertical profiles of rain rates and precipitation type partitioning using a combination of vertical and horizontal reflectivity gradients (Awaka et al. 1998; Steiner et al. 1995). The 13.8-GHz (Ku band) operational frequency can be attenuated in heavier rainfall; therefore, before rain rates are be derived, PR reflectivities are corrected using the hybrid methodology described by Iguchi et al. (2000, 2009), which is a combination of the surface reference technique (Meneghini et al. 2000) and the Hitschfeld and Bordan (1954) method. Using the precipitation type partitioning describe above, attenuation-corrected reflectivities are applied to individual $Z-R$ relationships to derive the vertical profile of rain rates within each $P R$ pixel.

\section{2) TRMM TMI 2A12 PRODUCT AND THE GPROF RAINFALL ALGORITHM}

TMI is a nine-channel passive microwave radiometer that observes brightness temperatures $\left(T_{b}\right)$ at five frequencies $(10.65,19.35,21.3,37.0$, and $85.5 \mathrm{GHz})$. The Goddard profiling algorithm (GPROF), introduced in Kummerow et al. (1996), utilizes a Bayesian framework to instantaneously retrieve hydrometer profiles by relating observed $T_{b}$ to entries in an a priori database, and it has been implemented operationally for multiple spaceborne radiometers, including the rain rates retrieved in the TMI $2 \mathrm{~A} 12$ rainfall product. The database contains sufficient entries to realistically represent climatological tropical cloud profiles, where each entry consists of matched PR rain rates averaged across each 21-GHz footprint $(\sim 19 \mathrm{~km} \times 31 \mathrm{~km})$ and TMI $T_{b}$ values at their native resolution. The application of Bayes's theorem allows for the derivation of the most probable rain rate using the observed set of TMI brightness temperatures,

$$
\operatorname{Pr}\left(R \mid T_{b}\right)=\operatorname{Pr}(R) \times \operatorname{Pr}\left(T_{b} \mid R\right),
$$

where $\operatorname{Pr}(R)$ is the probability of observing a rain profile $R$-in this case over the tropical oceans-and $\operatorname{Pr}\left(T_{b} \mid R\right)$ is the probability of one of the TMI channels observing a $T_{b}$ given a particular $R$ within the a priori database. The surface rain rate, the convective fraction of rainfall, and other atmospheric state parameters are derived by calculating their expected value from weighted a priori database entries. The current iteration of GPROF replaced a cloud-resolving-model-based database with an observationally generated database created using TRMM PR observations that are separated by surface temperature and total precipitable water (Kummerow et al. 2011), and it has recently expanded the Bayesian inversion for both land and ocean surface types (Kummerow et al. 2015). This work uses oceanic data from the version 7 TRMM data release, which utilizes GPROF 2010, version 2.

\section{c. NCAR dual-polarimetric S-PolKa radar}

The DYNAMO field campaign was launched to further understand the cloud and environmental processes that are necessary to initiate a Madden-Julian oscillation (MJO) event. The field experiment captured multiple MJO events throughout the campaign and was able to observe a wide variety of precipitating systems (e.g., Yoneyama et al. 2013; Johnson and Ciesielski 2013; Xu and Rutledge 2015). The National Center for Atmospheric Research (NCAR) S-band polarimetric radar and Ka-band (S-PolKa; 0.8-cm Ka band) radar located on the Addu Atoll $\left(0.63^{\circ} \mathrm{S}, 73.10^{\circ} \mathrm{E}\right)$ during the DYNAMO field campaign continuously collected data spanning 28 September 2011-15 January 2012, a time when deep convective activity was common as result of frequent MJO events. The data are gridded with a horizontal resolution of $2 \mathrm{~km}$ and a vertical resolution of $0.5 \mathrm{~km}$. Precipitation type partitioning is applied using the methods of Steiner et al. (1995) and rain rates are computed by a best-fit polarimetric algorithm described in Chandrasekar et al. (1990, 1993). The hybrid approach utilizes a combination of four $Z-R$ relations-1) $Z_{\mathrm{H}}$ only, 2) $Z_{\mathrm{H}}$ and $Z_{\mathrm{DR}}$, 3) $Z_{\mathrm{DR}}$ and $K_{\mathrm{DP}}$, or 4) $K_{\mathrm{DP}}$ only-depending on the measured magnitudes of the polarimetric variables. Full details of the S-Pol radar during the DYNAMO campaign can be found online (https://www.eol.ucar.edu/projects/dynamo/spol/).

\section{d. Conducting the TRMM comparisons}

To identify individual precipitating systems, we categorize their level of organization following the methodology described in Elsaesser et al. (2010). Known for their self-similar properties, the precipitation regimes 
TABLE 1. Summary of all precipitation regimes identified for the TRMM overpasses for Kwajalein and over the DYNAMO field campaign. The Kwajalein data were compared using coincident TRMM overpasses with the KPOL GV site for the period 2008-13. The DYNAMO data were taken from the S-PolKa radar dating from September 2011 to January 2012. Included are the total cases observed for each regime and their fraction of occurrence for observed cases.

\begin{tabular}{lccrr}
\hline & All cases identified & Shallow regime & Deep isolated regime & Organized regime \\
\hline Kwajalein KPOL & 438 & $123(29 \%)$ & $169(38 \%)$ & $146(32 \%)$ \\
DYNAMO S-Polka & 176 & $86(49 \%)$ & $54(31 \%)$ & $36(20 \%)$ \\
\hline
\end{tabular}

described in Elsaesser et al. (2010) have been used to relate numerous precipitation and atmospheric properties (e.g., Elsaesser and Kummerow 2013; Duncan et al. 2014; Hannah et al. 2016; Petkovic and Kummerow 2016; Henderson et al. 2017; Liu et al. 2016). All classified regimes throughout this manuscript were defined following the procedures of Elsaesser et al. (2010) and Elsaesser and Kummerow (2013) by implementing TRMM PR data to establish three distinct precipitation regimes, which are defined as follows: 1) shallow, typically warm rain, congestus clouds with echo tops commonly below $5 \mathrm{~km}$;2) deep unorganized convection; and 3) deep organized convection containing substantial amounts of deep stratiform rainfall. The classification takes advantage of the TRMM PR's ability to measure vertical profiles of hydrometeors to identify the level of system organization using precipitation depth (echo-top heights), rainfall intensity, and convective and stratiform contributions to the overall rainfall located within $1^{\circ} \times 1^{\circ}$ grid boxes along the TRMM PR swath. The advantage of the Elsaesser et al. (2010) classification lies in the fact that the defined precipitating systems are found to be self-similar in nature across the tropical oceans; thus, the validation statistics should be extendable to other oceanic regions observed by the TRMM satellite.

To compare satellite-based and ground-based rainfall retrievals at the Kwajalein site, multiple case studies from 2008 to 2013 are analyzed, while data from the DYNAMO campaign are obtained from the S-PolKa radar for all valid data collected from September 2011 to January 2012. For each TRMM orbit overpassing the Kwajalein or DYNAMO sites, rainfall occurring in a $1^{\circ} \times 1^{\circ}$ region within the $\mathrm{PR}$ swath, and contained within the ground radar volume sweep, are classified into one of the three precipitation regimes using TRMM PR information according to the classification process described above. Ground radar data and TMI data are matched using nearest neighbor to each $1^{\circ} \times 1^{\circ}$ region within the PR swath, and the mean rain rates over each $1^{\circ} \times 1^{\circ}$ region are compared. The ground-based rainrate estimates offer an independent quality-controlled dataset to be used for validation and will be considered the in situ truth when comparing rain rates and precipitation type (convective vs stratiform). Near-surface rain rates derived from the dual-polarized KPOL data are computed using the lowest radar plan position indicator (PPI) elevation scan and are interpolated to the 0.5-km CAPPI level. Rain rates from the S-PolKa radar reflectivity data are estimated using the lowest nonzero value of $Z$ between the surface to $2 \mathrm{~km}$ above ground level. The ground-based data present the best opportunity for validating the TRMM overpasses as a result of comparisons in a fully immersed oceanic environment and the ability of dual-polarized retrievals to represent precipitation variability occurring between precipitation regimes (Henderson et al. 2017).

Table 1 provides a summary of the number of cases identified for each regime in the Kwajalein and DYNAMO regions along with their respective percentage of the total. To optimize rainfall occurrence found within the Kwajalein GV-satellite overpasses and to minimize error as a result of differences in temporal sampling, cases are chosen where overpasses occur within 5 min between the ground and satellite overpasses, contain $5 \%$ or higher rain volume, and the nadir PR pixel occurs within $50 \mathrm{~km}$ of the ground-based radar. While the amount of rainfall within the radar scan varies for each overpass, on average each overpass yielded four individual cases that were classified into one of the three precipitation regimes. All overpasses are included for the DYNAMO campaign, where overpasses occur within 5 min between the ground and satellite overpasses within $100 \mathrm{~km}$ of the radar location.

\section{Comparison of rainfall retrieved between TRMM and ground observations}

\section{a. Kwajalein Atoll (western Pacific Ocean)}

To begin the validation process, we first check consistency with Wolff and Fisher (2008), who compared TRMM rain rates to the TRMM GV $2 \mathrm{~A} 53$ product and found both TMI and PR underestimate the GV retrievals, by $7.9 \%$ and $13.7 \%$, respectively. Bias is defined as the difference in rain rate expressed as a percentage [(TRMM - GV)/GV]. Using the Kwajalein 

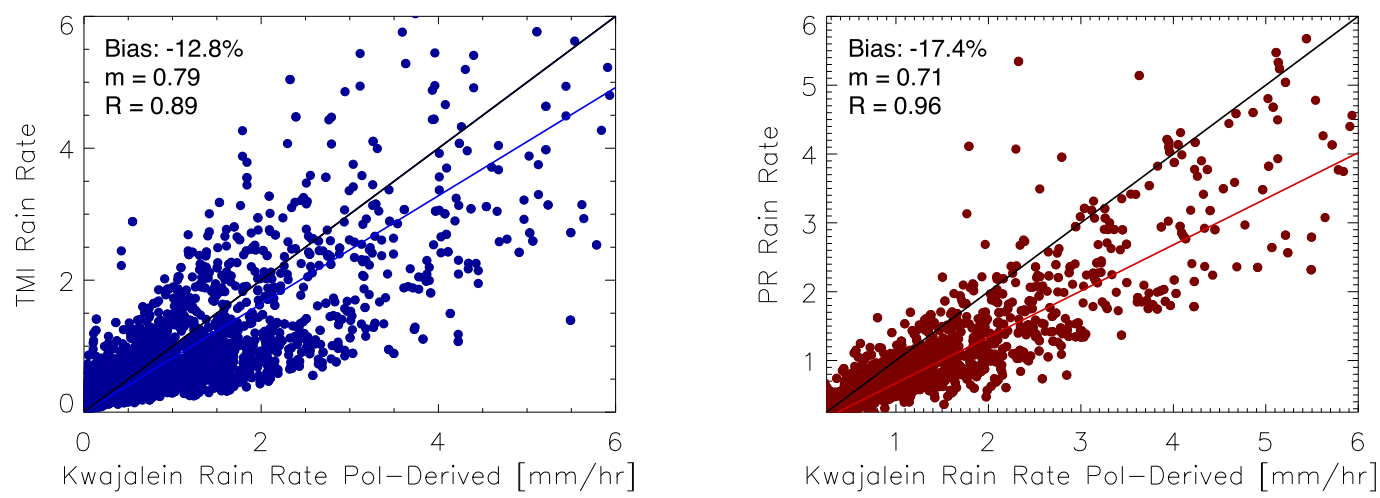

FIG. 2. Scatterplots of the (left) TMI and (right) PR vs Kwajalein GV rain-rate estimates for each $1^{\circ} \times 1^{\circ}$ box identified by the TRMM overpasses. Included in each panel is the bias, the slope of the best line fit, and the correlation with the GV estimates.

case studies, the biases between TRMM and the GV dual-polarized estimates yield underestimates of $12.8 \%$ and $17.4 \%$ for TMI and PR, respectively. This higher bias is expected, as the window probability matching method (WPMM)-based rain rates used in TRMM 2A53 have been found to underestimate the rain rates over the Kwajalein site (Henderson et al. 2017). If the 2A53 product is used for the case studies instead, we find a similar underestimation of $10.2 \%$ and $15.6 \%$ for TMI and PR, respectively. The bias estimates confirm the overall tendency for both TRMM retrievals to underestimate compared to validation rain rates at Kwajalein; however, when observing each case study individually, the sources of the bias can be more readily distinguished (Fig. 2). Figure 2 presents the compilation of mean rain rates calculated from TMI and PR compared to the dual-polarized-tuned GV estimates for all precipitation regime cases analyzed. Included in Fig. 2 are the correlation between the satellite product and $\mathrm{GV}$, percent bias, and slope of the best line fit. The TRMM 2A25 rain rates exhibit consistent underestimation compared to the GV estimates (Fig. 2b), whereas TMI 2A12 rain rates are highly variable with regions of both positively and negatively biased rain rates when compared to the Kwajalein GV rain rates (Fig. 2a). It can be hypothesized that the different regions of positive and negative bias are related to precipitation characteristics associated with different precipitation systems; this can be tested by applying the precipitation regime classification of Elsaesser et al. (2010) to the rain-rate comparisons.

Figure 3 presents comparisons of mean instantaneous rain rates averaged over each $1^{\circ} \times 1^{\circ}$ region from TMI and PR precipitation retrievals with GV separated by the precipitation regimes identified using Elsaesser et al. (2010). Based upon the regime separation, the TRMM $\mathrm{PR}$ rain rates exhibit systematically increasing bias categorized by system organization, where shallow precipitation is underestimated by $10.1 \%$, deep isolated convection is underestimated by $18.1 \%$, and organization convective systems are underestimated by $22.3 \%$. This pattern mimics what is found in previous work (e.g., Wolff and Fisher 2008, 2009; Rasmussen et al. 2013), where PR bias is generally related to precipitation intensity. For TMI, shallow convective systems for TMI and GV agree fairly well with TMI slightly overestimating the precipitation by $6.8 \%$, while like the PR biases, deep unorganized convective systems underestimate by $21.3 \%$. The bimodal bias pattern found with TMI rain-rate estimates is exemplified in the organized precipitation regime, where the overall bias is an underestimation of $9.1 \%$. The PR rain-rate comparisons help support the idea that biases are able to be distinguished through the precipitation regimes; however, TMI still exhibits positive and negative regions of bias associated with the organized convective systems. Recent work by Seo et al. (2015) discovered that positive differences between TMI and PR might be attributed to regions of stratiform rainfall contained within the TMI footprint/field of view (FOV).

Biases related to convective fraction within each precipitation regime reveal a clearer separation for both TMI and PR rain-rate estimates (Fig. 4). Using the matched Kwajalein rain rates within the $1^{\circ} \times 1^{\circ}$ regime classified using the PR data, we define the convective fraction as the fraction of total rainfall contributed by convective rainfall within each precipitation regime. A convective case is described where the convection fraction is $>0.50$ and a stratiform case where the convective fraction is $<0.50$. In Fig. 4 we see forefront patterns emerge in TMI and PR biases. First, there is a clear separation of biases between stratiform and convective cases in TMI, whereas PR typically underestimates all cases. TMI rain rates are overestimated compared to $\mathrm{GV}$ when the convective fraction is below 0.50 by 

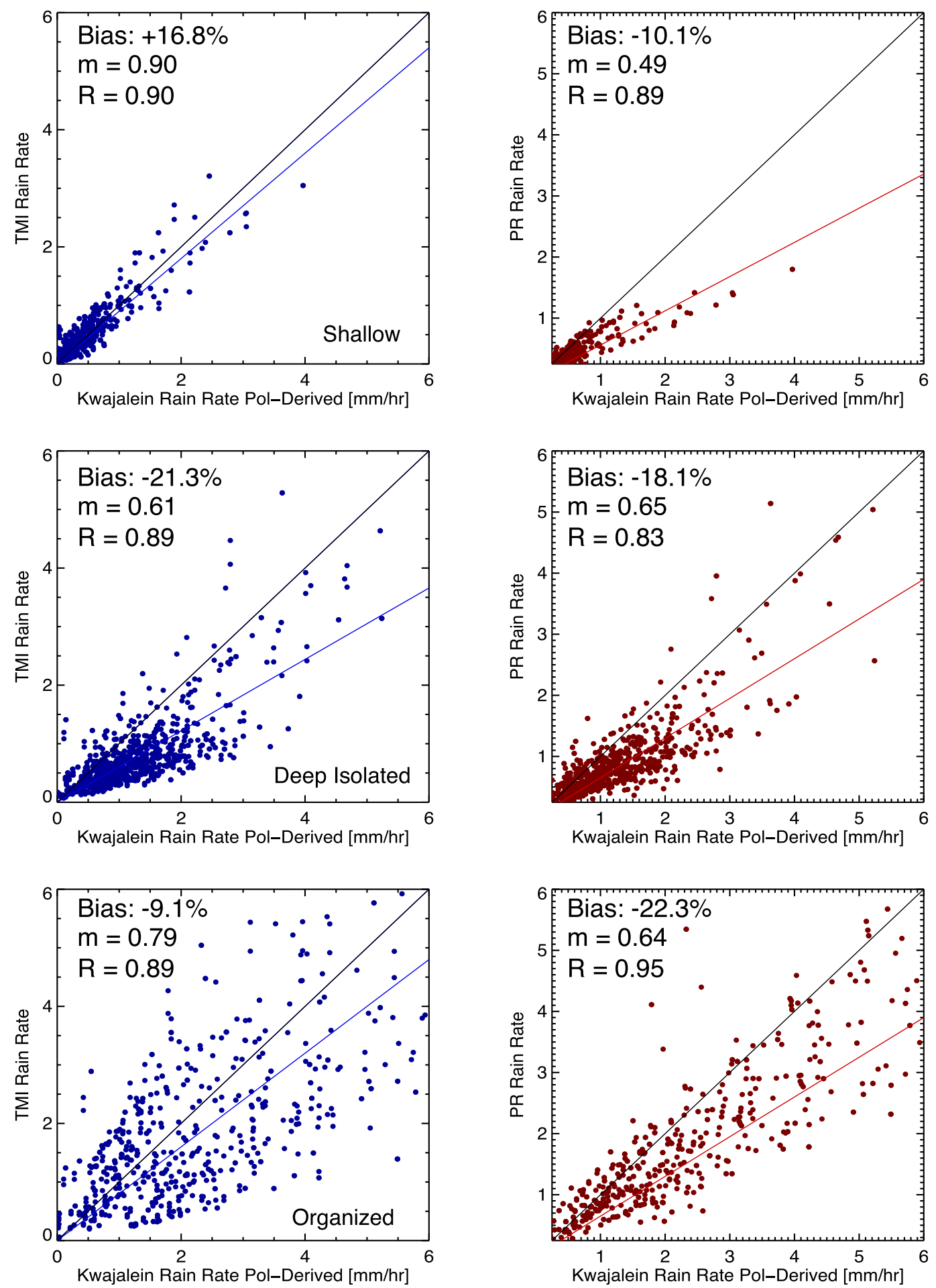

FIG. 3. As in Fig. 2, but split into the following precipitation regimes: (top) shallow, (middle) deep isolated, and (bottom) organized.

$27.9 \%$, whereas the PR retrieval exhibits improved comparisons with the GV analysis underestimating by $6.1 \%$ (Table 2). The positively biased portion of TMI comparisons are linked to organized systems containing predominately stratiform rainfall. As explained in Elsaesser et al. (2010), these organized convective 

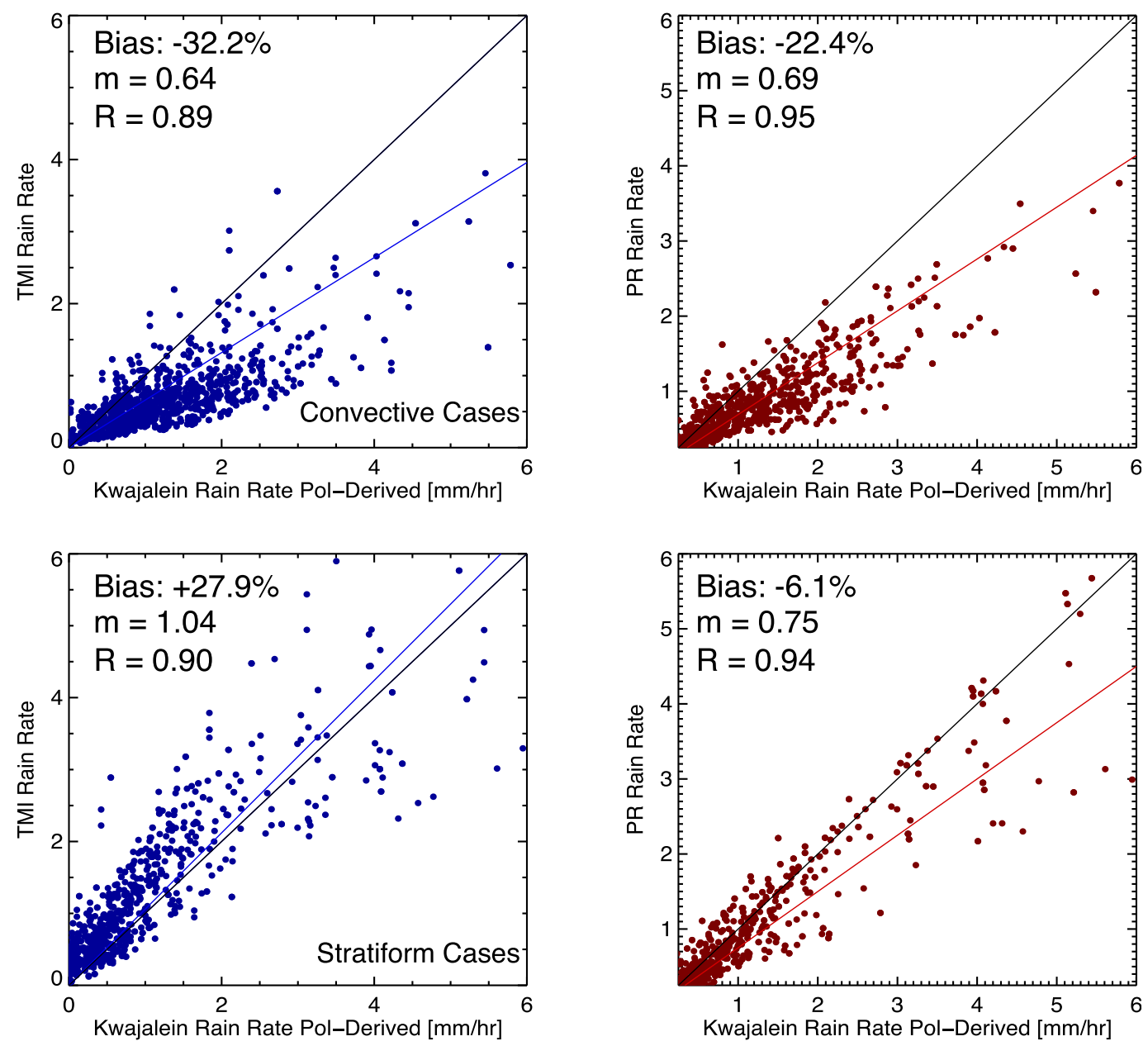

FIG. 4. As in Fig. 2, but as a function of convective fraction. (top) A convective case is described as having a convection fraction $>0.50$, and (bottom) a stratiform case is described as having a convective fraction $<0.50$. See Table 2 for validation statistics related to each precipitation regime.

systems are generally attributed to large deep anvil regions and a higher fraction of stratiform precipitation. When comparing TRMM and GV rain-rate estimates across the precipitation regimes, the largest differences between TRMM and GV occur with TMI rain rates where convective cases are underestimated by $37.8 \%$ in deep isolated regimes and stratiform cases are overestimated by $33.4 \%$ in organized regimes.

To further the rain-rate comparisons, the differences between TMI and the PR rain rates are also included in Table 2. For the predominantly stratiform cases, the largest discrepancies between TMI and PR occur within shallow and organized convective systems of $+38.8 \%$ and $+37.5 \%$, respectively. In shallow regimes, the TMIPR differences are due to underestimates by PR and overestimates with TMI compared to KPOL, whereas in organized regimes the differences originate more from the TMI overestimation of KPOL of $+33.4 \%$. The variability between PR and TMI differences is largely driven by TMI rain rates across the different regimes, which becomes evident within the deep isolated and organized regimes. In the predominantly stratiform cases, while opposite in sign, the TMI and PR biases are similar in magnitude, yielding a difference of $+23.5 \%$ within deep isolated precipitation regimes. This difference escalates to $+37.5 \%$ in organized regimes driven by an increase in bias of $25 \%$ in TMI rain rates. For convective rainfall cases, differences for each regime yield the following: $+10.9 \%$ for shallow convection, $-24.8 \%$ for deep isolated convection, and $-14.1 \%$ for organize convective systems. Both TMI and PR rain-rate estimates underestimate GV validation in convective cases; however, the TMI rain rates exhibit significant underestimation compared to the PR retrieval in deep isolated and organized regimes as well. 
TABLE 2. Bias statistics (\%) between the TRMM PR and TMI rain rates compared to the dual-polarized rain-rate estimates at the Kwajalein GV site as a function of precipitation regime. Also included are TMI and PR differences (\%) for each of the precipitation regimes. Values are first compared for convective cases (convection fraction $>0.50$ ) and then for stratiform cases (convection fraction $<0.50)$.

\begin{tabular}{lrrcc}
\hline & All & Shallow & Deep isolated & Organized \\
\hline Convective & & & & \\
PR bias & -22.4 & -12.8 & -23.4 & -26.1 \\
TMI bias & -32.2 & +5.5 & -37.8 & -30.3 \\
TMI - PR & -23.2 & +10.9 & -24.8 & -14.1 \\
Stratiform & & & & \\
PR bias & -6.1 & -11.4 & -8.4 & -2.6 \\
TMI bias & +27.9 & +25.5 & +8.1 & +33.4 \\
TMI - PR & +36.7 & +38.8 & +23.5 & +37.5 \\
\hline
\end{tabular}

\section{b. DYNAMO (central Indian Ocean)}

Data available from the DYNAMO field experiment provides a unique dataset to further examine the Kwajalein GV bias results. Across the Indian Ocean, the MJO is the dominant form of convective variability on intraseasonal scales, where cycles in deep convection occur approximately every 30-90 days. Even though a different synoptic environment influences the convection, similar regime-based bias patterns should still exist within the Indian Ocean; the regime-based precipitation characteristics described in Elsaesser et al. (2010) were found to be consistent across ocean basins. In this section we repeat our analysis utilizing the DYNAMO data to provide a consistency check on the regime-based biases that were observed over the Kwajalein GV region.

We extend the analysis to the central Indian Ocean to compare the TRMM PR and TMI retrievals to dualpolarimetric-tuned radar estimates from the S-PolKa radar. The S-PolKa radar completed measurements continuously from September 2011 to January 2012. Validation statistics are completed in the same manner as the Kwajalein analysis, where regimes are identified by TRMM PR and the mean rain rates are compared over $1^{\circ} \times 1^{\circ}$ regions. Validation statistics for all overpasses of the S-PolKa radar are presented in Table 3. Figure 5 presents the comparison of mean rain rates for TMI and PR overpasses compared to S-PolKa measurements derived during the DYNAMO campaign. Here the rain rates are presented with all raining cases and split into convective and stratiform cases using the definitions described above. Overall, both the TMI and $\mathrm{PR}$ rain rates display a similar pattern to the results found within the Kwajalein region.

When all systems are included in the bias calculation, we find a bias of $-13.6 \%$ and $-23.1 \%$ for the TMI and
TABLE 3. Bias statistics (\%) between the TRMM PR and TMI rain rates computed from the S-PolKa radar during the DYNAMO field campaign as a function of precipitation regime. Values are compared for all cases, convective cases (convection fraction $>0.50$ ), and stratiform cases (convection fraction $<0.50$ ).

\begin{tabular}{lcccc}
\hline \hline & All & Shallow & Deep isolated & Organized \\
\hline All cases & & & & \\
PR bias & -23.1 & -12.1 & -17.8 & -18.0 \\
TMI bias & -13.6 & +6.2 & -29.9 & -2.3 \\
Convective & & & & \\
PR bias & -17.9 & -0.5 & -17.7 & -27.8 \\
TMI bias & -40.4 & +13.0 & -36.9 & -32.2 \\
Stratiform & & & & \\
PR bias & -14.5 & -15.8 & -18.6 & -18.0 \\
TMI bias & +23.8 & +21.1 & +13.5 & +41.5 \\
\hline
\end{tabular}

PR rain rates, respectively (shown in Fig. 5). The bias patterns agree quite well with what was found using the KPOL radar rain estimates mentioned above. A similar pattern of scatter is found in TMI rain rates above and below the one-to-one line in Fig. 5a; therefore, the TRMM biases are still likely linked to convective and stratiform rainfall within each regime. Precipitating systems containing mostly convective rainfall are found to underestimate compared to the ground validation with biases ranging from $-0.5 \%$ to $-27.8 \%$ for $\mathrm{PR}$, and TMI heavily underestimates by $-36.9 \%$ and $-32.2 \%$ in deep isolated and organized regimes, respectively. This confirms that the TMI rain rate systematically underestimates GV and PR in these regimes (Table 3). Predominantly stratiform cases are generally underestimated for PR across the regimes, whereas TMI overestimates stratiform cases with biases ranging from +13.5 to +41.5 . The corresponding bias patterns in precipitation type and each precipitation regime are consistent over the DYNAMO field campaign region with results found using KPOL. The consistency in the bias patterns provides confidence that the regime-based bias results could be consistent in other oceanic environments.

\section{c. Convective and stratiform biases at the TMI footprint level}

Information content in deriving TMI and PR biases is increased when calculated as a function of their convective environments and split by their convective fractions. The clear bias patterns make a strong case for the use of regime-based analysis; however, they do not provide definitive proof that the TRMM biases are not related to variability in convective or stratiform precipitation types alone. The amount of convective and stratiform rainfall varies between each precipitation 

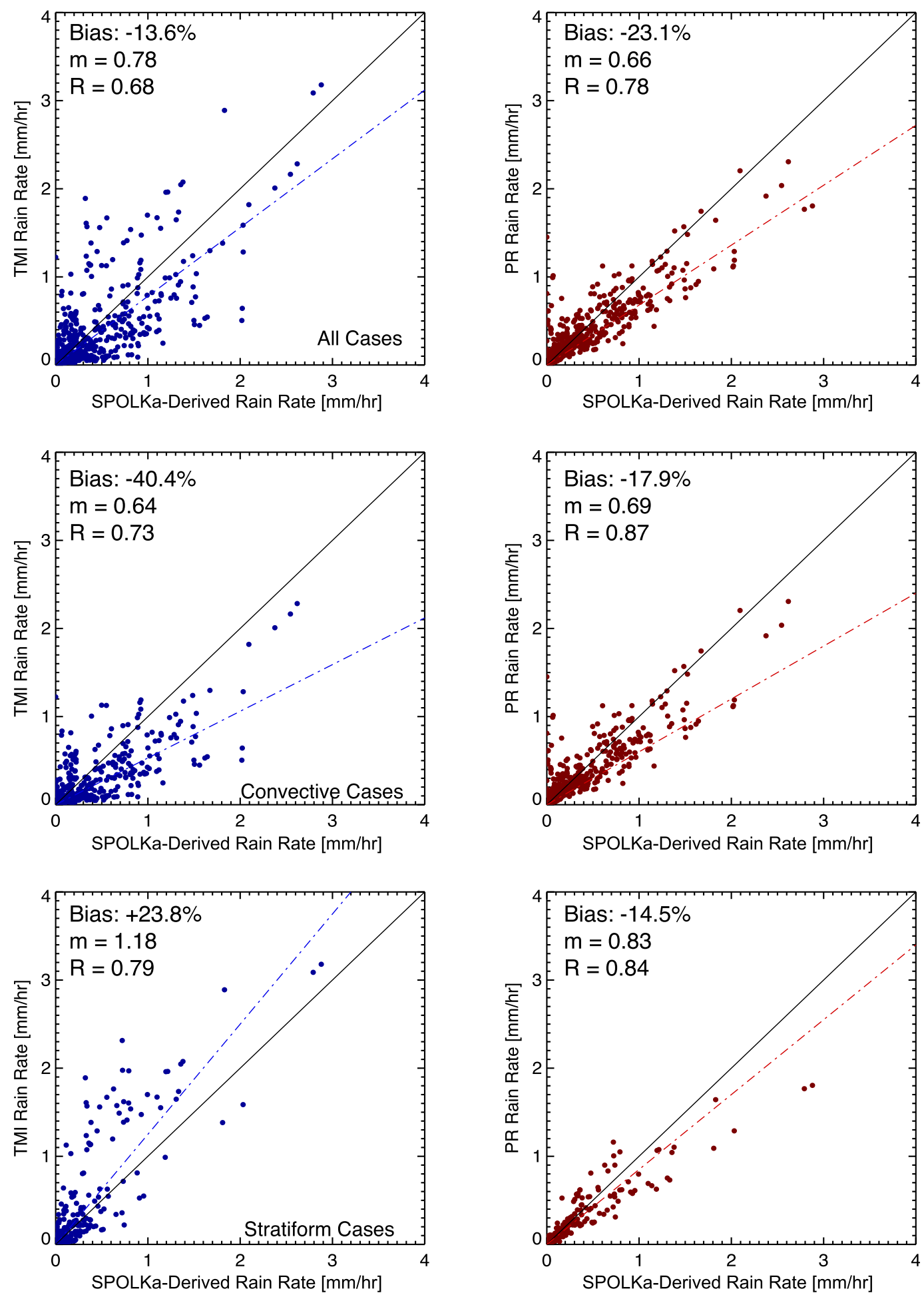

FIG. 5. As in Fig. 4, but derived from the DYNAMO field campaign. The results are included for (top) all cases, (middle) convective cases, and (bottom) stratiform cases. See Table 3 for validation statistics related to each precipitation regime. 
regime (Elsaesser et al. 2010; Henderson et al. 2017), where Elsaesser et al. (2010) find that the contribution of stratiform rainfall increases from $30 \%, 40 \%$, and $50 \%$ for shallow, deep isolated, and organized regimes, respectively. Because of the larger $1^{\circ} \times 1^{\circ}$ domain used to classify and examine precipitating systems, it remains plausible that biases associated with each precipitation regime are directed by systematic shifts in stratiform or convective rainfall, where biases could be invariant between the precipitation regimes. To examine this further, TMI and PR biases are derived at the TMI FOV scale for each precipitation regime at the Kwajalein GV site to isolate the direct impacts of convective and stratiform rainfall.

Validation on this scale is useful to ensure comparisons remain focused on each precipitation type, and using the TMI footprint scale aids in reducing random errors as a result of spatial and temporal discrepancies, which typically arise because of differing observing times between the satellite and ground radar (Houze et al. 2004).

Rain rates are compared following the footprint matching approach outlined in Wolff and Fisher (2008), who average PR and Kwajalein rain rates within a 7-km radius around each TMI-observed rain rate. Matched KPOL rain rates with the $7-\mathrm{km}$ radius are used to define convective and stratiform rainfall cases, defined where the convective or stratiform rainfall fraction exceeds $90 \%$ in the TMI FOV. The resulting comparisons are displayed in Fig. 6. The associated biases based upon the scatterplots in Fig. 6 are derived in the same manner as the validation statistics found in section 3 and are presented in Table 4. The biases found within the footprint scale are generally higher but expected, as large-scale averaging can smooth out bias estimates (Wolff and Fisher 2008); however, further bias separation is found as a function of its large-scale precipitation regime. It is also interesting to note that, while the TMI and PR biases are of larger magnitude, the two satellite estimates are in more agreement with each other than that of the GV rain rates at Kwajalein. For convective rain rates (Figs. 6a,c), TMI and PR still underestimate in nearly all cases overall. Here, the largest underestimation occurs in deep isolated precipitation regimes, where PR and TMI underestimate by $-52.2 \%$ and $-66.8 \%$, respectively. In stratiform rainfall, the continued pattern of TMI overestimating compared to both Kwajalein and PR is consistent through all regimes. TMI significantly overestimates Kwajalein rain rates by $92.3 \%$ within organized precipitation regimes, whereas PR slightly overestimates by $7.4 \%$. Both TMI and PR overestimate ( $49.4 \%$ and $24.0 \%$, respectively) in deep isolated convection.
Convective and stratiform biases are further examined by observing the mean rain rates for each sensor binned in $0.5 \mathrm{~mm} \mathrm{~h}^{-1}$ increments (Fig. 7). The PR retrieval compares best with Kwajalein rain rates for both convective and stratiform rainfall (Fig. 7a). As rainfall intensity increases, both PR and TMI heavily underestimate in convective rainfall, whereas TMI consistently underestimates PR. Within stratiform rainfall the PR retrieval matches well with Kwajalein for rain rates $<5 \mathrm{~mm} \mathrm{~h}^{-1}$, whereas TMI consistently overestimates Kwajalein in stratiform rainfall with a nearmonotonic increase in bias as a function of rain rate. The differences in rain rate as a function of regime are easily visualized (Figs. 7b,c). Notable differences occur between deep isolated precipitation regimes and organized regimes within convective FOVs. A clear distinction exists for convective pixels between the isolated and organized regimes for both TMI and PR, where deep isolated regimes are typically underestimated to a higher degree for all rain rates. For stratiform rainfall, positive biases are generally explained by overestimation within organized precipitation regimes, while overestimation from shallow and deep isolated regimes are constrained to lower rain rates. The convective and stratiform validation at the footprint level is able to define explicit positive and negative biases between the precipitation types; however, as described previously, the implementation of regime-based estimates becomes a necessary step to more accurately pinpoint bias sources.

\section{Regime-related biases}

\section{a. Precipitation regime variability over the Kwajalein region}

Figure 1 highlights the variability in regional TMI and PR differences occurring during different phases of ENSO. The validation results above describe distinct bias estimates for TMI and PR rain-rate retrievals created using the overpass comparisons. The comparisons occurred during both El Niño and La Niña events; therefore, it is likely that the biases should be representative of the regional convective variability that occurs during the various ENSO events (e.g., Masunaga et al. 2006). Based on the biases' results for each precipitation regime, it is presumed that the overestimation of TMI compared to PR during an El Niño event relates to a shift toward more organized precipitation containing significant amounts of stratiform rainfall.

To examine this, mean TMI and PR rain rates are compared for TRMM orbits within a $15^{\circ} \times 15^{\circ}$ region surrounding the Kwajalein Atoll for El Niño and La Niña events from 2002 to 2012. This period contains three El Niño and La Niña events, and rain rates were 

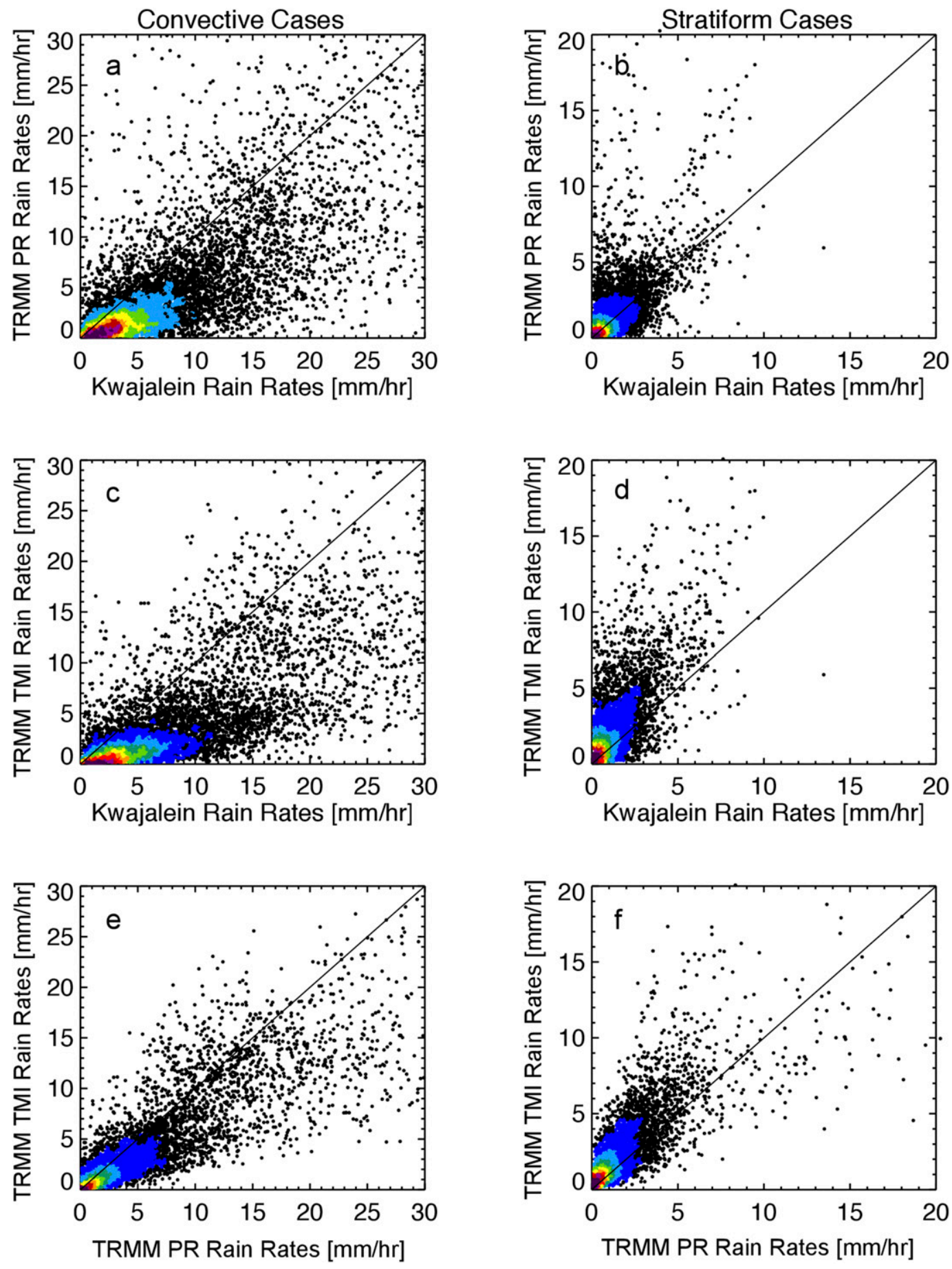

FIG. 6. Density plots of the comparisons made at the TMI footprint scale for convective and stratiform rainfall. Shown are comparisons with Kwajalein for (a) PR convective, (c) TMI convective, (b) PR stratiform, and (d) TMI stratiform. Differences between TMI and PR are shown in (e) for convective rain rates and (f) for stratiform rain rates. For (a)-(d), the abscissa axis is defined as the Kwajalein rain rate and the ordinate axis is defined as either the PR or TMI rain rate. For (e) and (f), the abscissa axis is defined as the PR rain rate and the ordinate axis is defined as the TMI rain rate. 
TABLE 4. Bias statistics for convective and stratiform rainfall at the TMI footprint scale between the TRMM PR and TMI rain rates. Also included are TMI and PR differences (\%) for each of the precipitation regimes. Rain rates are compared to the dualpolarized rain-rate estimates at the Kwajalein GV site as a function of precipitation regime.

All Shallow Deep isolated Organized

\begin{tabular}{llllr}
\hline Convective TMI FOV & & & & \\
PR bias & -34.8 & -15.9 & -52.2 & -28.6 \\
TMI bias & -50.9 & -30.9 & -66.8 & -47.9 \\
TMI - PR & -24.7 & -20.3 & -30.5 & -27.9 \\
Stratiform TMI FOV & & & & \\
PR bias & +17.2 & -22.4 & +24.0 & +7.4 \\
TMI bias & +77.8 & +13.2 & +49.4 & +92.3 \\
TMI - PR & +39.7 & +46.1 & +20.5 & +63.7 \\
\hline
\end{tabular}

retrieved after the TRMM orbit was boosted to $403 \mathrm{~km}$. An ENSO event is defined as when the ENSO-3.4 index reaches $\pm 0.5^{\circ} \mathrm{C}$; this is a common threshold set to determine such events (Trenberth 1997). For all cases, which includes all rainfall regardless of ENSO phase, over the 2002-12 period, the mean rain rate of $6.69 \mathrm{~mm} \mathrm{day}^{-1}$ for TMI, which is lower than the mean rain rate of $7.01 \mathrm{~mm} \mathrm{day}^{-1}$ from PR, yields an underestimation of $4.4 \%$ (Table 5). The differences between TMI and PR rain rates become further separated when evaluating over the ENSO events. TMI rain rates underestimate PR by $7.5 \%$ during La Niña events and overestimate PR by $10.3 \%$ during El Niño events. The TMI-PR differences during the El Niño and La Niña periods are not resultant of a single event but are found to be consistent throughout the TRMM record studied. Using the Mann-Whitney $U$ test to investigate the statistical differences of the rain-rate distributions, it was observed that mean TMI and PR monthly rain rates were significantly different from each other in both ENSO phases using a $95 \%$ significance threshold.

The variability of the precipitation regimes for each observed period is illustrated in Fig. 8. Shallow convective systems are most frequent; however, these systems contribute less to the overall accumulated rainfall. Compared to the mean state, La Niña events are characterized by shallow convective systems and deep isolated convective systems, whereas organized systems are more prevalent during El Niño events-occurring nearly twice as frequent compared to La Niña events. Further, during an El Niño event, organized systems are more likely to be stratiform cases, as denoted by the nearly $60 \%$ of classified systems containing predominantly stratiform rainfall (Fig. 8b). This result agrees with the biases found in section 3 , where an increase in organized systems should correspond with TMI overestimating against both GV and PR rain rates.
This is further manifested by looking at the fraction of total rainfall for each precipitation regime (Figs. 8c,d).

For both PR and TMI, shallow convective systems contribute similar amounts to the total rainfall with a maximum contribution occurring during La Niña events. Discrepancies between the two retrievals occur with deep isolated precipitation regimes and the organized precipitation regimes. In the mean state, the highest contributions to $\mathrm{PR}$ rain rates derive from deep isolated systems (43.4\%), while TMI rain rates have a higher contribution from organized systems (45.5\%). During an El Niño or La Niña event, both retrievals agree on which precipitation regime provides the most rainfall; however, TMI favors organized rainfall to a higher degree with $58.0 \%$ of rainfall reported from organized convection compared to $53.9 \%$ from PR, where the $4 \%$ disparity in PR is made up from rainfall occurring in deep isolated precipitation regimes.

The differences in the two rainfall retrievals appear to be related to the frequency of precipitation regimes observed. The results suggest that during an El Niño event, there is a systematic shift toward more organized precipitation containing large precipitating stratiform regions. Increases in stratiform rainfall have been observed within satellite estimates and models associated with an increase in SST, such as during an El Niño event (e.g., Schumacher and Houze 2003; Schumacher et al. 2004; Masunaga et al. 2006; Houze et al. 2004; Posselt et al. 2012), and the increased discrepancy between TMI and PR rain rates appear to be directly related to variability in the organized regimes.

To examine this further, we deconstruct the systematic differences occurring between TMI and PR to their respective precipitation regimes. Figure 9 displays the contribution to TMI-PR rain-rate differences by each precipitation regime and convective fraction. The differences are derived using the same period and $15^{\circ} \times 15^{\circ}$ region surrounding the Kwajalein GV site as above. Figure 9a displays the contribution from convective- and stratiform-only biases derived using the TMI footprint matching methodology described in section $3 \mathrm{c}$. It is clear that the ENSO-related differences between TMI and PR could be comprehended through only convective and stratiform rain rates. The substantial increase in stratiform differences during the El Niño events are directly related to an increase in stratiform occurrence of raining pixels (Fig. 9b). For raining pixels, stratiform occurrence increases from $61 \%$ during the mean state to $72 \%$ on average across the El Niño events. The use of convective and stratiform pixels is able to explain the differences over the ENSO periods; however, it is the collective information provided by the regime-based analysis that provides the proper source and magnitude 

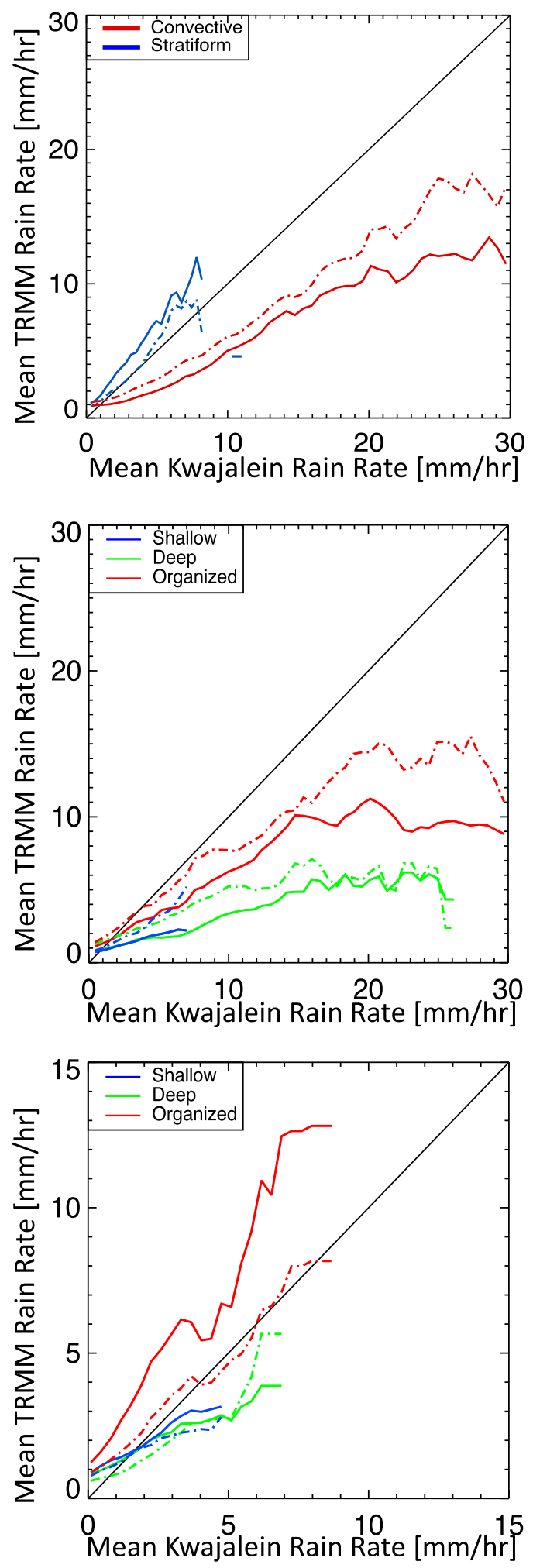

FIG. 7. Comparisons of the PR (dashed) and TMI (solid) mean rain rates with the dual-polarized estimates from the KPOL radar. Comparisons are made at the TMI footprint scale for convective and stratiform rainfall. Rain-rate profiles as shown for (top) all
TABLE 5. Statistics of mean TMI and PR rain rates $\left(\mathrm{mm} \mathrm{day}^{-1}\right)$ during the periods from 2002 to 2010, El Niño events, and La Niña events. Mean rain rates are derived within a $15^{\circ} \times 15^{\circ}$ region surrounding the Kwajalein Atoll.

\begin{tabular}{lccc}
\hline \hline & All & El Niño & La Niña \\
\hline Rain bias & & & \\
PR & 7.01 & 7.69 & 5.43 \\
TMI & 6.69 & 8.48 & 5.02 \\
TMI - PR (\%) & -4.4 & +10.3 & -7.5 \\
Corrected & & & \\
PR & 7.66 & 8.56 & 5.91 \\
TMI & 7.49 & 8.85 & 5.78 \\
TMI - PR (\%) & -2.2 & +3.4 & -3.6 \\
\hline
\end{tabular}

of the uncertainties. For the mean state and La Niña events, the overall negative TMI-PR difference is derived from differences occurring in convective rainfall cases within deep isolated and organized regimes; however, the observed pattern differs during the El Niño events (Fig. 9c). The TMI-PR differences during the El Niño events yield a positive bias for stratiform cases in organized regimes nearly double that of the mean state and accounts for $81 \%$ of the overall bias. The increase is directly related to the organized precipitation regime, which also displayed the largest TMI and PR differences in stratiform rainfall at the pixel level (Table 4). During La Niña events, the rainfall contribution shifts toward deep isolated systems, which also are characterized by more convective raining pixels compared to the mean state and El Niño.

\section{b. Application of regime-based biases}

To assess the degree to which these bias estimates aid in explaining differences in interannual variability, we apply a bias correction for TMI and PR rain rates at the $1^{\circ}$ scale based on the differences from the KPOL GV rain rates. Application of the biases derived using the Kwajalein GV estimates should aid our understanding of the correct distribution of rainfall between the precipitation regimes, their overall impact on TMI and PR differences, and further our understanding of the regional precipitation climatology. The advantage of this methodology is that the validation statistics are physically related to the self-similar precipitation regimes without assuming either the TMI or PR satellite retrievals are correct.

\section{$\leftarrow$}

matched convective and stratiform cases, (middle) convective-only cases segregated by regime, and (bottom) stratiform-only cases segregated by regime. 

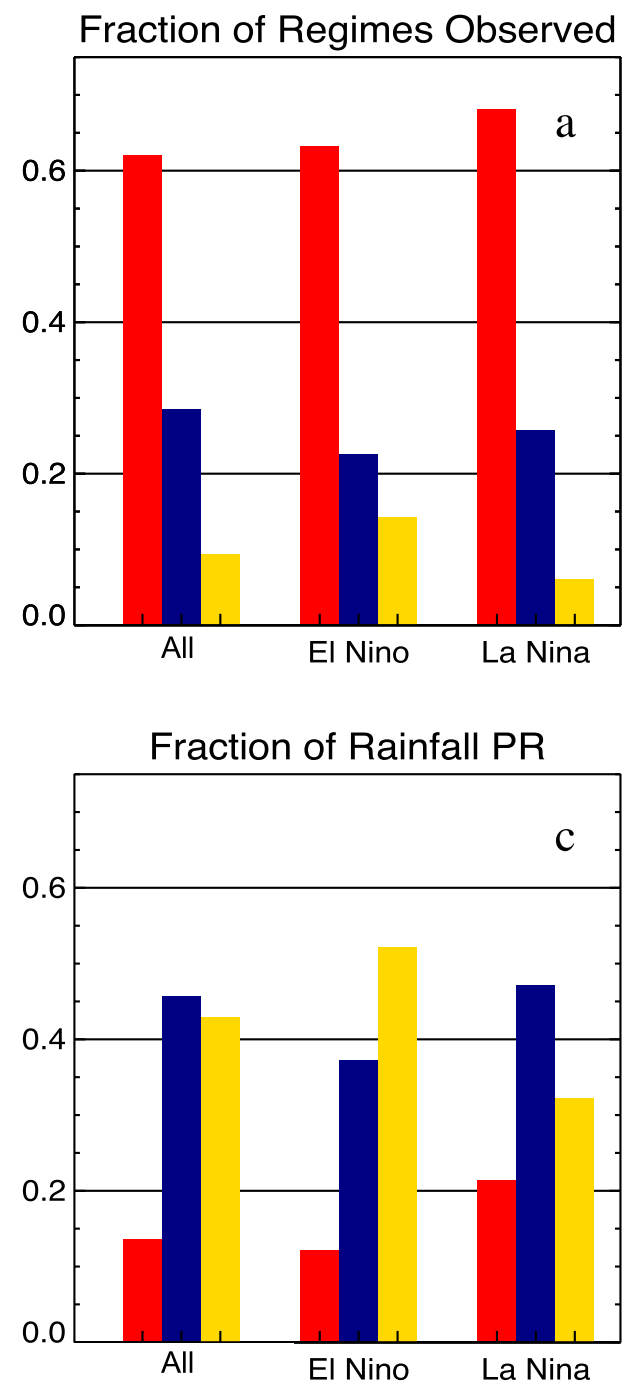
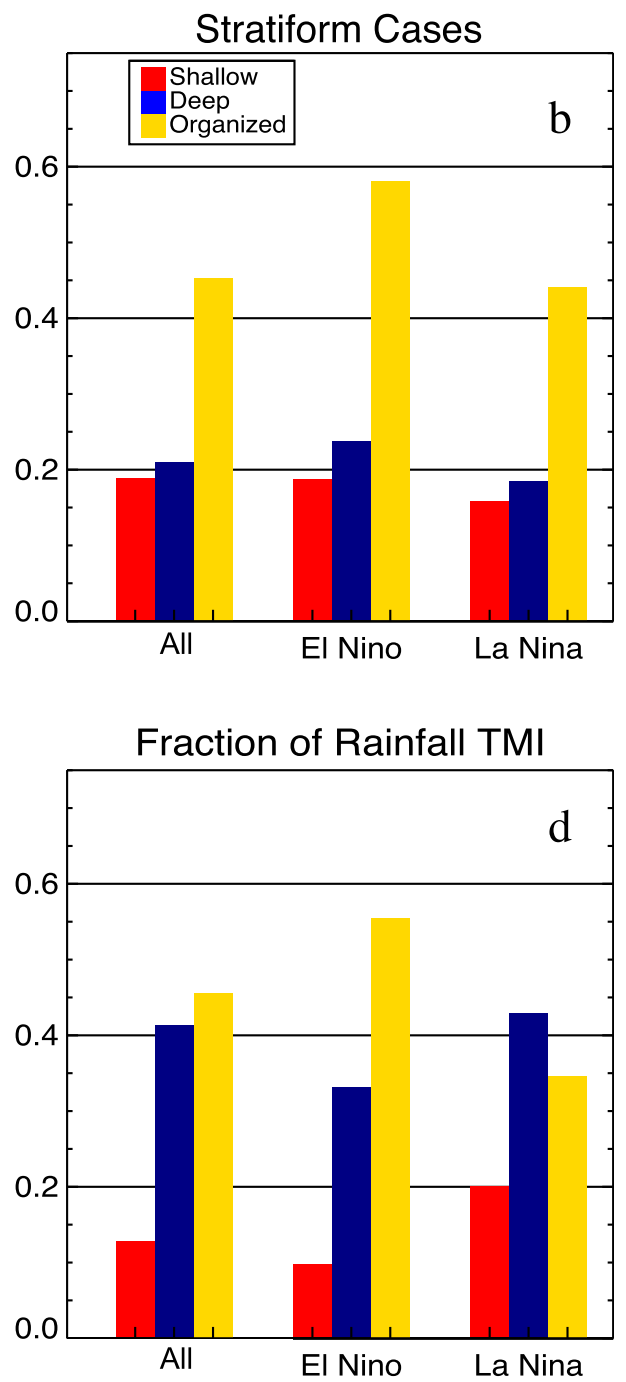

FIG. 8. Precipitation-regime-based statistics for PR and TMI rain rates for periods from 2002 to 2010, El Niño events, and La Niña events. (a) The occurrence of each precipitation regime over each period. (b) The fraction of each precipitation regime identified as a stratiform case (convective fraction is $<0.50$ ). Fraction of rainfall contributed by each precipitation regime for (c) PR and (d) TMI rain rates.

To begin, precipitation regimes are identified from 2002 to 2012 within the $15^{\circ} \times 15^{\circ}$ region described above and a bias correction is applied for each precipitation regime and their convective or stratiform cases using ratios derived from the bias estimates described in section $3 \mathrm{a}$ within Table 2 . The resulting rain rates and TMI-PR differences are presented in Table 5, and the resulting fraction of rainfall for each regime contributing to the total rain rate are illustrated in Fig. 10. The difference in rainfall fraction per regime is greatly reduced. Over the mean state, El Niño events, and La Niña events, both TMI and PR retrievals now agree on the precipitation regime that contributes the most to rainfall. As a result, the gap between TMI and PR are reduced for each period analyzed. Overall, the rain rates are increased slightly for both sensors, which is expected because both were found to underestimate the GV data. While TMI still underestimates PR for all cases and La Niña events, the difference is reduced to $-2.2 \%$ overall and $-3.6 \%$ for La Niña events. Further, the difference between TMI and PR during El Niño events is greatly reduced from $+10.3 \%$ to $+3.4 \%$. When applying significance testing similar to the abovementioned section, the significance does not hold after the application of the bias correction and therefore the TMI and PR mean monthly rain rates do not have significantly different rainfall distributions after the bias correction is applied. The improvement in rainfall between TMI and PR 

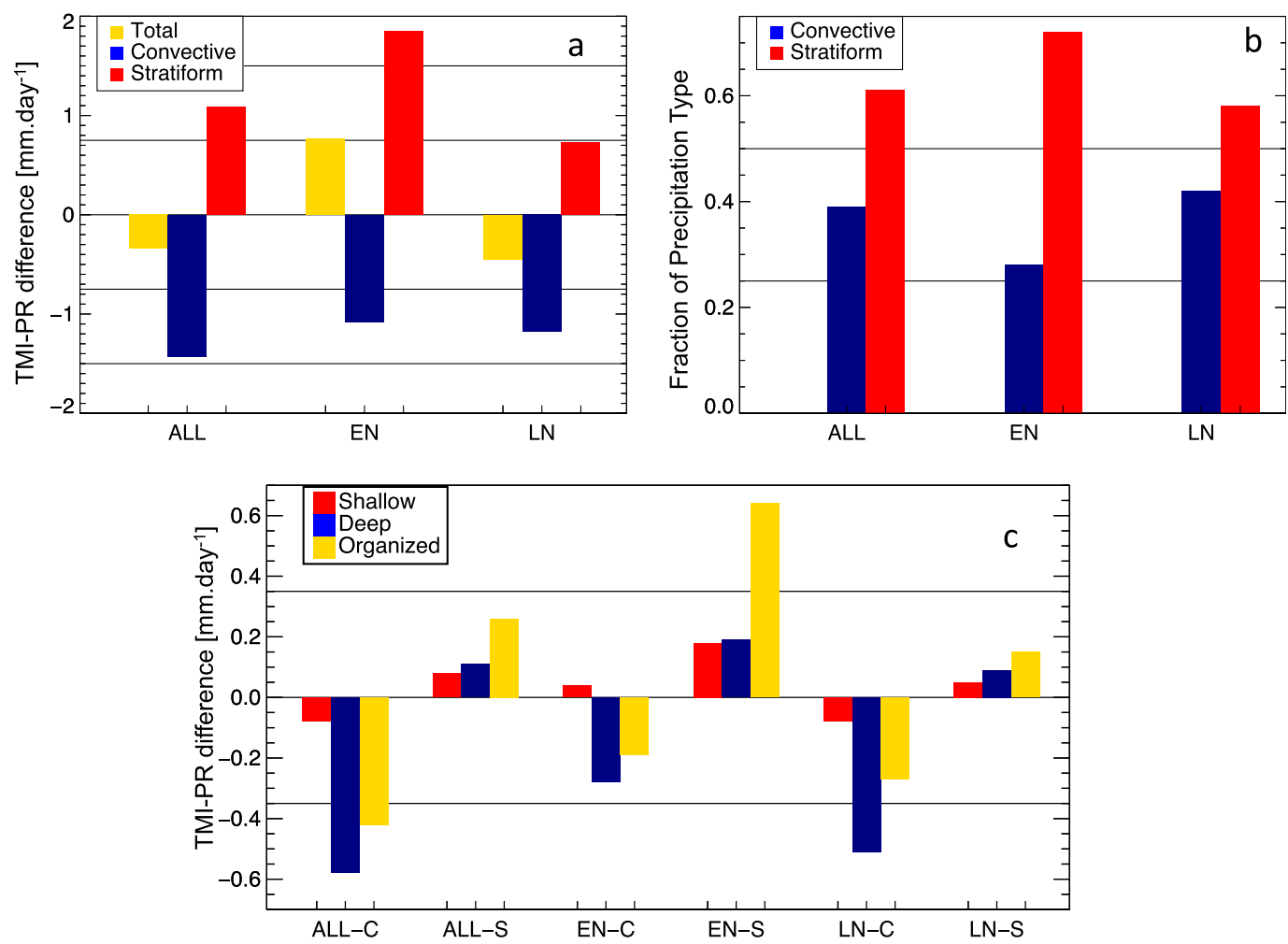

FIG. 9. Contributions to TMI-PR rain-rate differences as a function of convective/stratiform rainfall and precipitation regime. TMI-PR rain-rate differences are for periods from 2002 to 2010 (ALL), El Niño events (EN), and La Niña events (LN). Biases are first explained for (a) only convective and stratiform rainfall over the TMI footprint and (b) their occurrence. They are then explained by (c) the precipitation regimes, which are further split by convective fraction into convective cases $(\mathrm{C})$ and stratiform cases (S).

demonstrates that the self-similar precipitation regimes provide a strong relationship to precipitation biases and provide a simple and effective technique for validating satellite retrievals and aiding in precipitation uncertainty diagnosis.

\section{Examining retrieval biases}

The results outlined thus far have demonstrated that TRMM oceanic biases are dependent on both the rainfall regime and the partitioning of stratiform and convective rainfall. For the PR rain-rate retrieval, recent work has documented the underestimation of surface precipitation estimates for convective rainfall to errors related to the drop size distribution parameter, which tends to negatively bias the $Z-R$ calculations of rain rate (e.g., Iguchi et al. 2009; Munchak et al. 2012; Bringi et al. 2012). Based on GPROF's physical dependence on the radar for its a priori database, and the PR retrieval general underestimation compared to the ground radar, underestimation in convective cases for TMI would also be expected; however, in predominantly convective cases, the TMI retrieval also underestimates PR by nearly
$27.8 \%$ and $14.1 \%$ in deep isolated regimes and organized regimes, respectively, and for all convective cases when observed at the footprint scale. When retrieving rain rates using a Bayesian approach, biases can be introduced because of the fact that all raining profiles are included in the weighted mean. Negative biases can exist where the Bayesian retrieval is unable to completely distinguish observed brightness temperatures from those within the database, allowing the inclusion of lighter-rain profiles during higher-rain-intensity cases. Similarly, the inclusion of all convective and stratiform FOVs in the weighting process may also lead to biases (Seo et al. 2015) if brightness temperatures within the raining FOV are not distinguishable between convective and stratiform rainfall.

We first inspect this issue by evaluating the TMI retrieval representation of convective rainfall in relation to TMI and PR differences for all precipitation regimes identified within the $15^{\circ} \times 15^{\circ}$ region described above spanning a 3-yr period from 2008 to 2010 . For the TMI GPROF retrieval, the convective fraction is derived using the PR-based Bayesian database; along with the rain rate, for each TMI FOV the convective fraction is 
Corrected Fraction of Rainfall PR

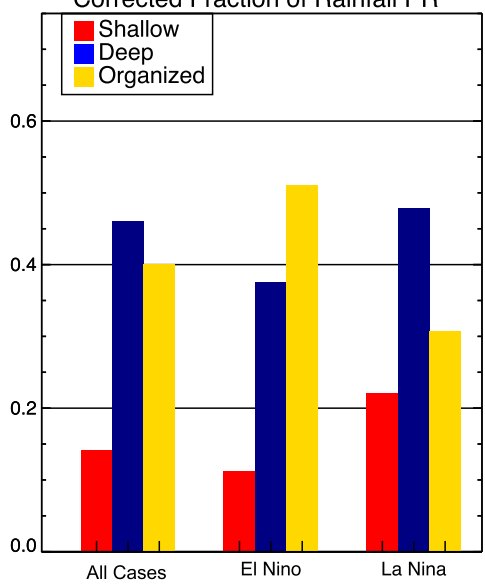

Corrected Fraction of Rainfall TMI

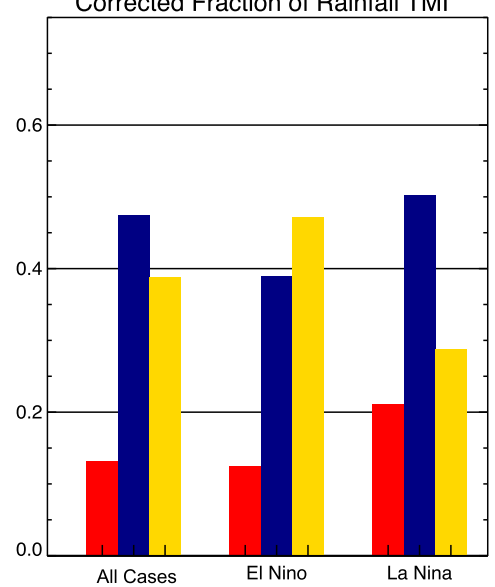

TMI-PR Difference [\%]

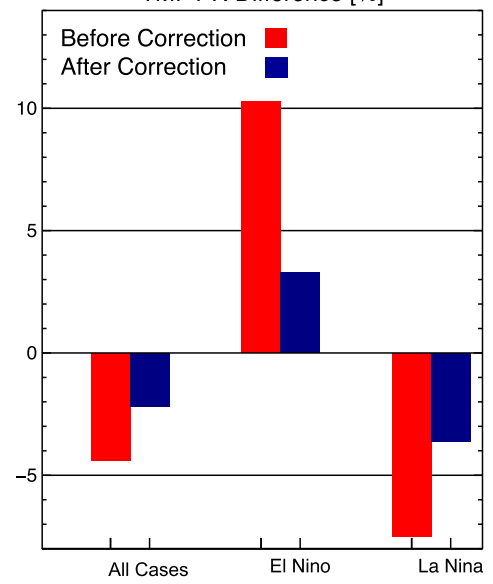

FIG. 10. Precipitation-regime-based statistics for PR and TMI rain rates for periods from 2002 to 2010, El Niño events, and La Niña events. Fraction of rainfall contributed by each precipitation regime for (left) PR and (middle) TMI rain rates after rain rates were corrected based upon their ratio to the Kwajalein dual-polarized rain-rate estimates. (right) TMI-PR difference before (red) and after (blue) bias correction.

derived from multiple PR observations in the Bayesian database and weighted by how well they match the observed values of $T_{b}$. For each $1^{\circ} \times 1^{\circ}$ region, the mean GPROF convective fraction and the PR convective fraction will be compared to each other. For these comparisons, the PR definition of convective and stratiform raining pixels is now considered "ground truth" for the convective fraction of rainfall. The PR precipitation type classification generally agrees well with GV-source comparisons (Schumacher and Houze 2000; Kirstetter et al. 2015; Henderson et al. 2017). Kirstetter et al. (2015) discovered that PR precipitation type classifications could be misclassified when large rainfall variability was found in the TRMM PR FOV; however, for $1^{\circ} \times 1^{\circ}$ regions, the mean PR rain rates and convective fractions occurring within each precipitation regime were found to be in good agreement with GV data at Kwajalein (Henderson et al. 2017). In Fig. 11, we derive the difference in mean rainfall for all identified precipitation regimes as a function of convective fraction within each $1^{\circ} \times 1^{\circ}$ region for both the TMI and PR retrievals. Figure 11a presents the differences for all precipitation regimes, while Figs. $11 \mathrm{~b}-\mathrm{d}$ present the differences associated with each specific precipitation regime. Overall, the differences agree with the abovementioned $\mathrm{GV}$ results.

At the highest PR-determined convective fractions, TMI underestimates PR rain rates and overestimates $\mathrm{PR}$ rain rates within lower convective fractions. Notably, the GPROF retrieval struggles to accurately differentiate between convective and stratiform rainfall. PR rain rates span the entire spectrum of convective fractions, whereas TMI rain rates are limited, particularly in organized convection, where convective fractions are generally constricted between $30 \%$ and $60 \%$. The precipitation regimes demonstrate that the differences between the TMI and PR retrievals are not uniform but in fact vary uniquely for each regime, which demonstrates another advantage of evaluating precipitation uncertainty through the use of precipitation regimes.

The TRMM biases described in sections 3 and 4 demonstrate that pixel-level variations in convective and stratiform rainfall can begin to characterize TMIPR differences over time. To investigate how the lack of precipitation type partitioning may impact the GPROF retrieval at the pixel level, we conduct a sensitivity analysis by constraining the GPROF a priori database by the observed convective rainfall fraction. The GPROF a priori database (Kummerow et al. 2011) contains the necessary information to test the Bayesian retrieval: brightness temperatures for each of the nine TMI frequency channels, a PR-based rain rate convolved to the TMI FOV, and their respective convective rainfall fraction from PR. The a priori data entries within the database are used as "observational" input to GPROF to calculate theoretical errors as a function of rain rate and convective fraction. The observed data points are taken within the a priori database for SST values ranging from 290 to $305 \mathrm{~K}$ and column water vapor ranging from 30 to $55 \mathrm{~mm}$. These values are commonly observed within the deep tropics, where large TMI-PR differences are found (e.g., Fig. 1). It is important to note that the a priori PR rain rate will now be considered truth and improvements found within the GPROF retrieval may likely still contain biases when 

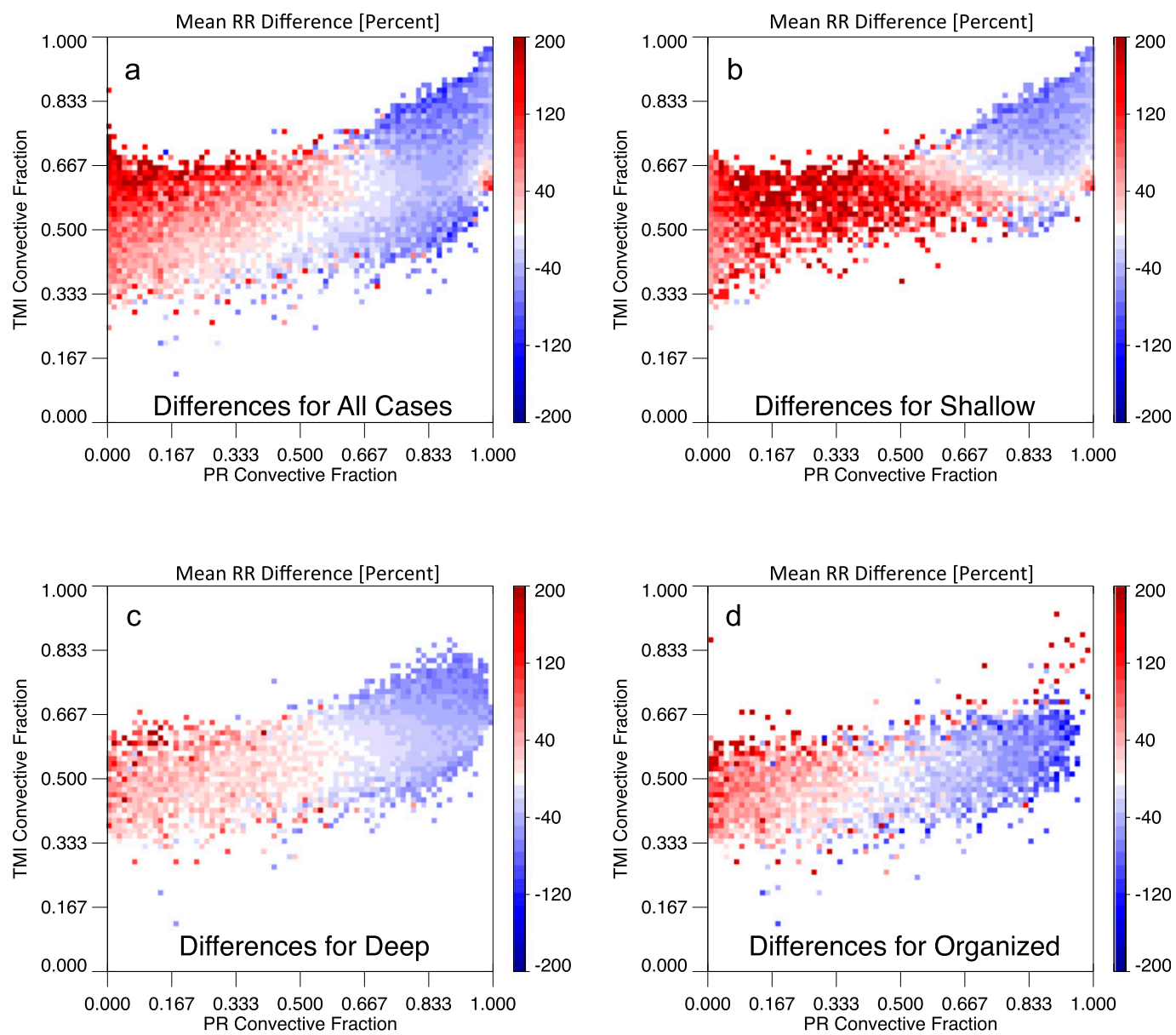

FIG. 11. TMI-PR differences within a $15^{\circ} \times 15^{\circ}$ region surrounding the Kwajalein Atoll as a function of convective fraction and precipitation regime. Differences are calculated over a 3-yr period (2008-10) for (a) all cases, and rain rates within (b) shallow precipitation regimes, (c) deep isolated precipitation regimes, and (d) organized precipitation regimes.

compared to GV data. The GPROF retrieval is first tested in its natural state (control) and then the procedure is repeated constraining the convective fraction to $\pm 15 \%$ of the observed convective fraction and $\pm 30 \%$ of the observed convective fraction. The convective fraction is constrained by limiting the Bayesian a priori database to include only data points with a convective fraction either $\pm 15 \%$ or $\pm 30 \%$ of the observed convective fraction of rainfall; therefore, it will include only raining profiles with similar convective characteristics.

Rain-rate biases in GPROF, as a function of rainfall intensity and convective fraction, are shown in Fig. 12 for the control case. In a similar manner as the GV results, biases become positive as stratiform rainfall becomes predominant and largely negative for heavier raining convective scenes. The majority of rainfall occurs where biases are either slightly negative or positive (rain rates $<2 \mathrm{~mm} \mathrm{~h}^{-1}$ ); however, a significant amount of comparisons occur where biases are large (rain rates $>2 \mathrm{~mm} \mathrm{~h}^{-1}$ ). While not as frequent, these higherintensity rain rates contribute toward the majority of total rainfall (Berg et al. 2010). A substantial improvement in GPROF-related biases is found when the database is constrained by the convective fraction (Fig. 13). When the convective fraction is constrained to $\pm 15 \%$, a reduction in bias of $>60 \%$ is commonly found with biases reduced up to $80 \%$ in higher convective fractions. In stratiform cases, the majority of biases are reduced by $70 \%-80 \%$. The overall improvement when the convective fraction is constrained to $\pm 30 \%$ is lower, but the reduction in bias is still significant. There is still a remnant negative bias that occurs as a function of rain intensity; however, this example demonstrates that even roughly identifying the convective fraction could provide significant reductions in TMI and PR oceanic rainrate differences. 
SST: $290 \mathrm{~K}-305 \mathrm{~K}, \mathrm{CWV}: 35-55 \mathrm{~mm}$
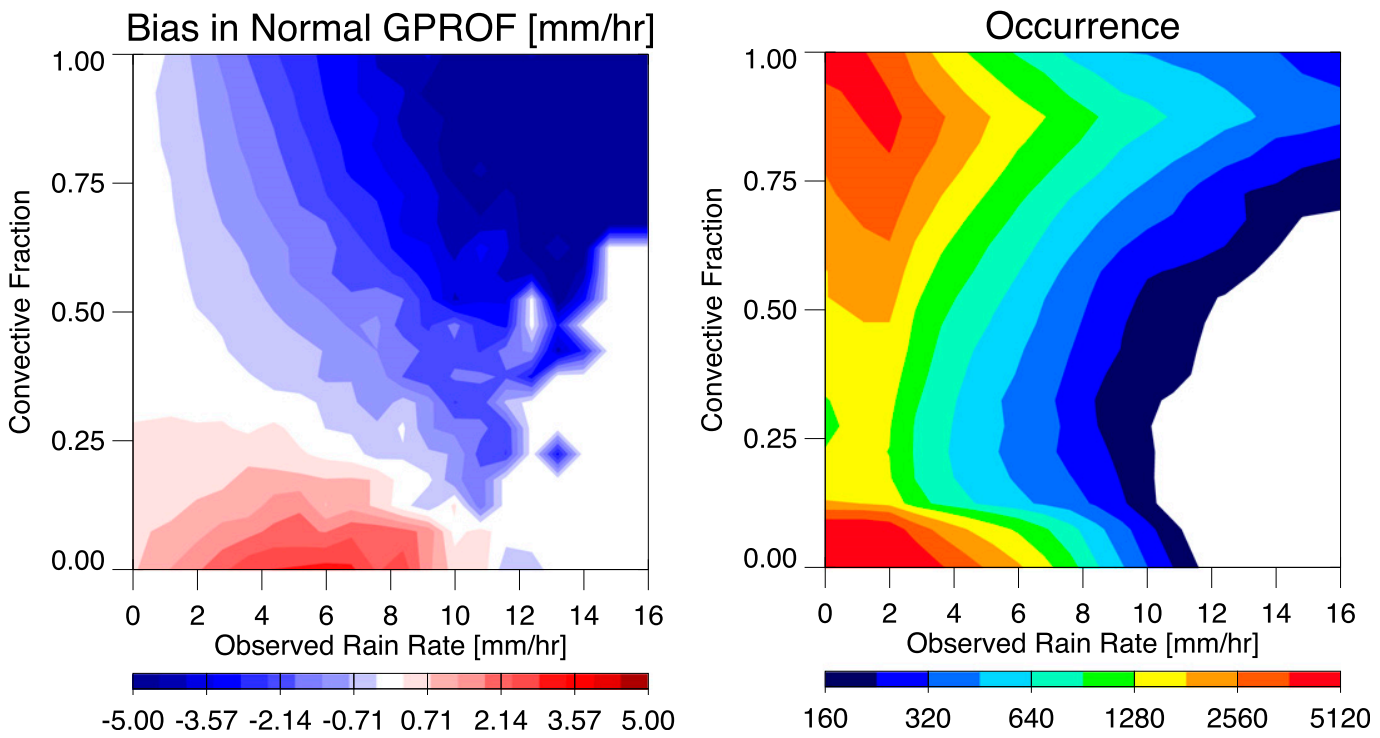

FIG. 12. (left) Differences between GPROF-retrieved rain rates and observed rain rates, where the a priori entries in the database are used as observational input into GPROF to calculate theoretical errors occurring as a function of rain rate and convective fraction. (right) The occurrence of each rain-rate comparison as a function of rain rate and convective fraction.

\section{Conclusions}

The TRMM satellite has provided a foundational observing system for studying precipitation characteristics across the tropics. Throughout the TRMM mission, research employed various efforts to validate the TRMM rainfall retrievals; however, we still lack an understanding of the sources of bias. This issue is particularly pertinent during El Niño and La Niña events, where regional differences between the TRMM retrievals lead to large discrepancies when averaged over the tropical oceans. This manuscript attempts to better understand biases in TRMM rain-rate estimates by comparing TRMM instantaneous rain rates to ground sources with respect to distinct self-similar precipitation regimes.

To begin, TMI and $\mathrm{PR}$ rain rates are compared to ground validation rain rates at the Kwajalein Atoll and measurements taken during the DYNAMO field campaign. The results demonstrate that distinct bias patterns in TMI and PR rain-rate estimates exist when biases are associated with the precipitation regimes and their respective convective fractions. In particular, when compared to the Kwajalein GV rain rates, TMI exhibits the largest biases within organized convection systems, which are biased by $+33.4 \%$ in stratiform cases and negatively biased by $-37.8 \%$ for convective cases. The bias patterns for both PR and TMI are consistent when observed at the larger $1^{\circ} \times 1^{\circ}$ scale and at the TMI footprint scale when split into convective and stratiform components. An analysis at the TMI footprint level reveals the pixel-level biases in stratiform rain are largest in TMI rain rates, which overestimate by $92.3 \%$ in organized regimes, whereas the biases in convective rain rates are driven by deep isolated regimes, where TMI and PR underestimate by $66.8 \%$ and $52.2 \%$, respectively. The sources of TRMM PR biases have been attributed not only to reflectivity corrections needed for attenuation but also to the variability of precipitation occurring in the PR FOV, which can lead to misclassification of precipitation type and inaccuracy in the $Z-R$ rain relationships (Kirstetter et al. 2014, 2015). Further, the TMI biases within this work expand upon issues found in convective and stratiform partitioning described in Carr et al. (2015), who found TMI rainfall underestimates to be related to issues in properly diagnosing the convective fraction related to the inhomogeneity of precipitation within the TMI FOV. The largest biases occurred within more extreme rain rates, similar to the biases observed in section 5 .

Analysis of the precipitation regime variability in the west Pacific reveals close correspondence between the differences in TMI and PR rainfall and the frequency of occurrence of each precipitation regime. The application of bias correction demonstrates the ability of the precipitation regimes to explain the differences found between TMI and PR over the different periods. Most notable during El Niño events, TMI-PR differences are 


\section{SST: 290K-305K, CWV: $35-55 \mathrm{~mm}$}
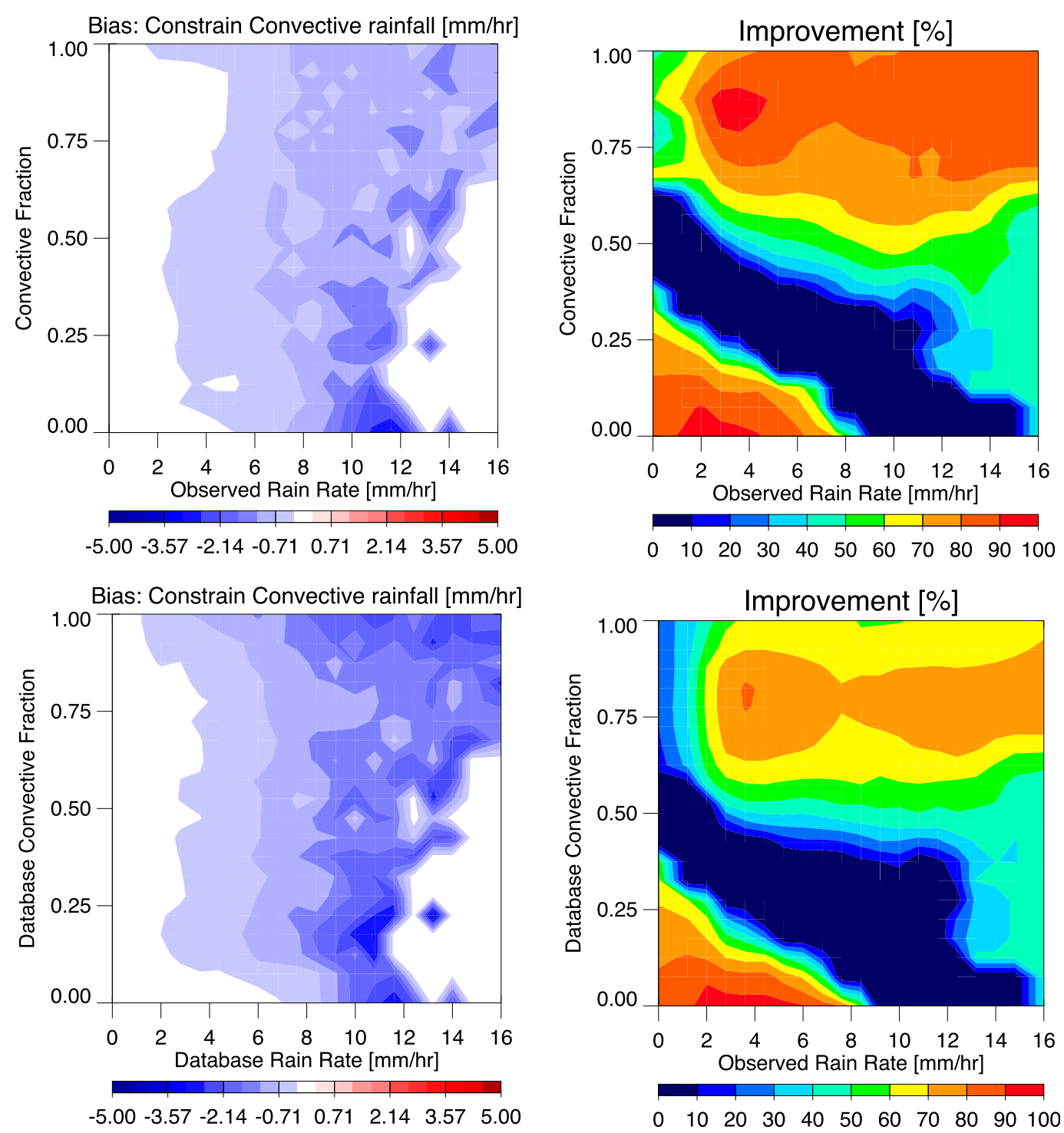

FIG. 13. As in Fig. 10, but (left) differences between GPROF-retrieved rain rates and observed rain rates when constraining the convective fraction in the Bayesian procedures by (top) $\pm 15 \%$ of the observed convective fraction and (bottom) $\pm 30 \%$ of the observed convective fraction. (right) The improvement in bias when the convective fraction is constrained (top) by convective fraction and (bottom) $\pm 30 \%$ of the observed convective fraction.

reduced from $10.3 \%$ to $3.4 \%$ and a significant reduction was also found during La Niña events. Further exploration into biases within Bayesian retrievals reveals that the biases may be related to differentiating between convective and stratiform rainfall. GPROF struggles to properly diagnose the convective fraction of rainfall, leading to biases dependent on the precipitation regime being observed. Constraining the selection of a priori data points within the Bayesian framework by the convective fraction reduces biases in the GPROF retrieval, where we find that the magnitudes of GPROF biases can be reduced upward of $70 \%-80 \%$ in many areas. The improved results indicated that improving the GPROF Bayesian framework could involve further stratification of the a priori database to ensure the raining scenes are properly weighted within convective and stratiform rainfall types.

The precipitation regimes implemented in this work provide physical sources to relate each TMI and PR bias. The self-similar nature of the regimes provides the potential application of the results across the tropical oceans and becomes a useful methodology to begin 
diagnosing climate-scale uncertainties in precipitation products. To this end, we emphasize that understanding and reconciling the differences in actively versus passively retrieved products through the use of precipitation regimes will prove helpful for continued assessment of time-varying situation-dependent biases and for continuing to aid in the development and validation of the Global Precipitation Measurement (GPM; Hou et al. 2014) or other precipitation-related studies.

Acknowledgments. This research was supported by PMM Grants NNX16AE23G and NNX13AG30G (recipient: Wesley Berg). The authors wish to acknowledge Dr. Gregory Elsaesser (NASA GISS) for his comments and suggestions on this work, and Dr. Steven Rutledge (CSU) and Dr. Elizabeth Thompson (CSU) for providing the DYNAMO data and for their helpful comments. The authors thank Dr. David Randel (CSU) for providing and assisting with running the GPROF retrieval. Finally, we thank the three anonymous reviewers, who provided excellent suggestions to improve the quality of the manuscript.

\section{REFERENCES}

Adler, R. F., J.-J. Wang, G. Gu, and G. J. Huffman, 2009: A tenyear tropical rainfall climatology based on a composite of TRMM products. J. Meteor. Soc. Japan, 87A, 281-293, https:// doi.org/10.2151/jmsj.87A.281.

_- G. Gu, and G. J. Huffman, 2012: Estimating climatological bias errors for the Global Precipitation Climatology Project (GPCP). J. Appl. Meteor. Climatol., 51, 84-99, https://doi.org/ 10.1175/JAMC-D-11-052.1.

Alexander, M. A., I. Bladé, M. Newman, J. R. Lanzante, N. Lau, and J. D. Scott, 2002: The atmospheric bridge: The influence of ENSO teleconnections on air-sea interaction over the global oceans. J. Climate, 15, 2205-2231, https://doi.org/ 10.1175/1520-0442(2002)015<2205:TABTIO >2.0.CO;2.

Awaka, J., T. Iguchi, and K. Okamoto, 1998: Early results on rain type classification by the Tropical Rainfall Measuring Mission (TRMM) precipitation radar. Proc. Eighth URSI Commission F Open Symp., Aveiro, Portugal, URSI, 143-146.

Berg, W., C. Kummerow, and C. Morales, 2002: Differences between east and west Pacific rainfall systems. J. Climate, 15, 3659-3672, https://doi.org/10.1175/1520-0442(2002)015<3659: DBEAWP $>2.0 . \mathrm{CO} ; 2$.

_ gimes: The relationship of regional TRMM rainfall biases to the environment. J. Appl. Meteor. Climatol., 45, 434-454, https://doi.org/10.1175/JAM2331.1.

,-- , and J. M. Haynes, 2010: The distribution of rainfall over oceans from spaceborne radars. J. Appl. Meteor. Climatol., 49, 535-543, https://doi.org/10.1175/2009JAMC2330.1.

Bringi, V.N., T. Tang, and V. Chandrasekar, 2004: Evaluation of a new polarimetrically based $Z-R$ relation. J. Atmos. Oceanic Technol., 21, 612-623, https://doi.org/10.1175/1520-0426(2004)021<0612: EOANPB $>2.0 . \mathrm{CO} ; 2$.

— , G.-J. Huang, S. J. Munchak, C. D. Kummerow, D. A. Marks, and D. B. Wolff, 2012: Comparison of drop size distribution parameter (D0) and rain rate from S-band dual-polarized ground radar, TRMM precipitation radar (PR), and combined PR-TMI: Two events from Kwajalein Atoll. J. Atmos. Oceanic Technol., 29, 1603-1616, https://doi.org/10.1175/ JTECH-D-11-00153.1.

Carr, N., and Coauthors, 2015: The influence of surface and precipitation characteristics on TRMM TMI rainfall retrieval uncertainty. J. Hydrometeor., 16, 1596-1614, https://doi.org/ 10.1175/JHM-D-14-0194.1.

Chandrasekar, V., V. N. Bringi, N. Balakrishnan, and D. S. Zrnić, 1990: Error structure of multiparameter radar and surface measurements of rainfall. Part III: Specific differential phase. J. Atmos. Oceanic Technol., 7, 621-629, https://doi.org/ 10.1175/1520-0426(1990)007<0621:ESOMRA>2.0.CO;2.

_ E. Gorgucci, and G. Scarchilli, 1993: Optimization of multiparameter radar estimates of rainfall. J. Appl. Meteor., 32, 1288-1293, https://doi.org/10.1175/1520-0450(1993)032<1288: OOMREO $>2.0 . \mathrm{CO} ; 2$.

Duncan, D. I., C. D. Kummerow, and G. S. Elsaesser, 2014: A Lagrangian analysis of deep convective systems and their local environmental effects. J. Climate, 27, 2072-2086, https:// doi.org/10.1175/JCLI-D-13-00285.1.

Elsaesser, G. S., and C. D. Kummerow, 2013: A multisensor observational depiction of the transition from light to heavy rainfall on subdaily time scales. J. Atmos. Sci., 70, 2309-2324, https://doi.org/10.1175/JAS-D-12-0210.1.

,-- T. T. L'Ecuyer, Y. N. Takayabu, and S. Shige, 2010: Observed self-similarity of precipitation regimes over the tropical oceans. J. Climate, 23, 2686-2698, https://doi.org/ 10.1175/2010JCLI3330.1.

Hannah, W. M., B. E. Mapes, and G. S. Elsaesser, 2016: A Lagrangian view of moisture dynamics during DYNAMO. J. Atmos. Sci., 73, 1967-1985, https://doi.org/10.1175/ JAS-D-15-0243.1.

Held, I. M., and B. J. Soden, 2006: Robust responses of the hydrological cycle to global warming. J. Climate, 19, 5686-5699, https://doi.org/10.1175/JCLI3990.1.

Henderson, D. S., C. D. Kummerow, and D. A. Marks, 2017: Sensitivity of rain-rate estimates related to convective organization: Observations from the Kwajalein, RMI, radar. J. Appl. Meteor. Climatol., 56, 1099-1119, https://doi.org/ 10.1175/JAMC-D-16-0218.1.

Hitschfeld, W., and J. Bordan, 1954: Errors inherent in the radar measurement of rainfall at attenuating wavelengths. J. Meteor., 11, 58-67, https://doi.org/10.1175/1520-0469(1954)011<0058: eiitrm>2.0.co;2.

Hou, A. Y., and Coauthors, 2014: The Global Precipitation Measurement (GPM) Mission. Bull. Amer. Meteor. Soc., 95, 701-722, https://doi.org/10.1175/BAMS-D-13-00164.1.

Houze, R. A., Jr., S. Brodzik, C. Schumacher, S. E. Yuter, and C. R. Williams, 2004: Uncertainties in oceanic radar rain maps at Kwajalein and implications for satellite validation. J. Appl. Meteor., 43, 1114-1132, https://doi.org/10.1175/ 1520-0450(2004)043<1114:UIORRM > 2.0.CO;2.

Iguchi, T., T. Kozu, R. Meneghini, J. Awaka, and K. Okamoto, 2000: Rain-profiling algorithm for the TRMM precipitation radar. J. Appl. Meteor., 39, 2038-2052, https://doi.org/10.1175/ 1520-0450(2001)040<2038:RPAFTT $>2.0 . C O ; 2$.

, — J. Kwiatkowski, R. Meneghini, J. Awaka, and K. Okamoto, 2009: Uncertainties in the rain profiling algorithm for the TRMM precipitation radar. J. Meteor. Soc. Japan, 87A, 1-30, https://doi.org/10.2151/jmsj.87A.1.

Johnson, R. H., and P. E. Ciesielski, 2013: Structure and properties of Madden-Julian oscillations deduced from DYNAMO 
sounding arrays. J. Atmos. Sci., 70, 3157-3179, https://doi.org/ 10.1175/JAS-D-13-065.1.

Kirstetter, P. E., and Coauthors, 2012: Toward a framework for systematic error modeling of spaceborne precipitation radar with NOAA/NSSL ground radar-based National Mosaic QPE. J. Hydrometeor., 13, 1285-1300, https://doi.org/10.1175/ JHM-D-11-0139.1.

, Y. Hong, J. J. Gourley, Q. Cao, M. Schwaller, and W. Petersen, 2014: Research framework to bridge from the Global Precipitation Measurement Mission core satellite to the constellation sensors using ground-radar-based National Mosaic QPE. Remote Sensing of the Terrestrial Water Cycle, V. Lakshmi et al., Eds., Wiley, 61-79, https://doi.org/10.1002/ 9781118872086.

,,--- M. Schwaller, W. Petersen, and Q. Cao, 2015: Impact of sub-pixel rainfall variability on spaceborne precipitation estimation: Evaluating the TRMM 2A25 product. Quart. J. Roy. Meteor. Soc., 141, 953-966, https://doi.org/ 10.1002/qj.2416.

Kummerow, C. D., W. S. Olson, and L. Giglio, 1996: A simplified scheme for obtaining precipitation and vertical hydrometeor profiles from passive microwave sensors. IEEE Trans. Geosci. Remote Sens., 34, 1213-1232, https://doi.org/10.1109/ 36.536538 .

_ - W. Barnes, T. Kozu, J. Shiue, and J. Simpson, 1998: The Tropical Rainfall Measuring Mission (TRMM) sensor package. J. Atmos. Oceanic Technol., 15, 809-817, https://doi.org/ 10.1175/1520-0426(1998)015<0809:TTRMMT>2.0.CO;2.

—, S. Ringerud, J. Crook, D. Randel, and W. Berg, 2011: An observationally generated a priori database for microwave rainfall retrievals. J. Atmos. Oceanic Technol., 28, 113-130, https://doi.org/10.1175/2010JTECHA1468.1.

, D. L. Randel, M. Kulie, N.-Y. Wang, R. Ferraro, S. J. Munchak, and V. Petkovic, 2015: The evolution of the Goddard profiling algorithm to a fully parametric scheme. J. Atmos. Oceanic Technol., 32, 2265-2280, https://doi.org/ 10.1175/JTECH-D-15-0039.1.

Liu, C., and E. Zipser, 2014: Differences between the surface precipitation estimates from the TRMM precipitation radar and passive microwave radiometer version 7 products. J. Hydrometeor., 15, 2157-2175, https://doi.org/10.1175/ JHM-D-14-0051.1.

Liu, J., C. D. Kummerow, and G. S. Elsaesser, 2016: Identifying and analyzing uncertainty structures in the TRMM Microwave Imager precipitation product over tropical ocean basins. Int. J. Remote Sens., 38, 23-42, https://doi.org/10.1080/ 01431161.2016.1259676.

Marks, D. A., D. B. Wolff, D. S. Silberstein, A. Tokay, J. L. Pippitt, and J. Wang, 2009: Availability of high-quality TRMM ground validation data from Kwajalein, RMI: A practical application of the relative calibration adjustment technique. J. Atmos. Oceanic Technol., 26, 413-429, https://doi.org/10.1175/ 2008JTECHA1174.1.

Masunaga, H., and C. D. Kummerow, 2005: Combined radar and radiometer analysis of precipitation profiles for a parametric retrieval algorithm. J. Atmos. Oceanic Technol., 22, 909-929, https://doi.org/10.1175/JTECH1751.1.

— T. S. L'Ecuyer, and C. D. Kummerow, 2005: Variability in the characteristics of tropical precipitation systems. Part I: Spatial structure. J. Climate, 18, 823-840, https://doi.org/10.1175/ JCLI-3304.1.

Meneghini, R., T. Iguchi, T. Kozu, L. Liao, K. Okamoto, J. A. Jones, and J. Kwiatkowski, 2000: Use of the surface reference technique for path attenuation estimates from the TRMM precipitation radar. J. Appl. Meteor., 39, 2053-2070, https:/doi.org/ 10.1175/1520-0450(2001)040<2053:UOTSRT > 2.0.CO;2.

Munchak, S. J., C. D. Kummerow, and G. Elsaesser, 2012: Relationships between the raindrop size distribution and properties of the environment and clouds inferred from TRMM. J. Climate, 25, 2963-2977, https://doi.org/10.1175/ JCLI-D-11-00274.1.

Nesbitt, S. W., E. J. Zipser, and C. D. Kummerow, 2004: An examination of version-5 rainfall estimates from the TRMM Microwave Imager, precipitation radar, and rain gauges on global, regional, and storm scales. J. Appl. Meteor., 43, 1016-1036, https://doi.org/10.1175/1520-0450(2004)043<1016: AEOVRE $>2.0 . C O ; 2$.

Petkovic, V., and C. D. Kummerow, 2016: Understanding the sources of satellite passive microwave rainfall retrieval systematic errors over land. J. Appl. Meteor. Climatol., 56, 597-614, https://doi.org/10.1175/JAMC-D-16-0174.1.

Posselt, D. J., S. C. van den Heever, G. L. Stephens, and M. R. Igel, 2012: Changes in the interaction between tropical convection, radiation, and the large-scale circulation in a warming environment. J. Climate, 25, 557-571, https://doi.org/10.1175/ 2011JCLI4167.1.

Powell, S. W., and R. A. Houze Jr., 2013: The cloud population and onset of the Madden-Julian Oscillation over the Indian Ocean during DYNAMO-AMIE. J. Geophys. Res. Atmos., 118, 11 979-11 995, https://doi.org/10.1002/2013JD020421.

Rasmussen, K. L., S. L. Choi, M. D. Zuluaga, and R. A. Houze Jr., 2013: TRMM precipitation bias in extreme storms in South America. Geophys. Res. Lett., 40, 3457-3461, https://doi.org/ 10.1002/grl.50651.

Schumacher, C., and R. A. Houze Jr., 2000: Comparison of radar data from the TRMM satellite and Kwajalein oceanic validation site. J. Appl. Meteor., 39, 2151-2164, https://doi.org/ 10.1175/1520-0450(2001)040<2151:CORDFT > 2.0.CO;2.

— and - 2003: Stratiform rain in the tropics as seen by the TRMM Precipitation Radar. J. Climate, 16, 1739-1756, https:// doi.org/10.1175/1520-0442(2003)016<1739:SRITTA > 2.0.CO;2.

,$- \ldots$, and I. Kraucunas, 2004: The tropical dynamical response to latent heating estimates derived from the TRMM precipitation radar. J. Atmos. Sci., 61, 1341-1358, https://doi. org/10.1175/1520-0469(2004)061<1341:TTDRTL > 2.0.CO;2.

Seo, E.-K., B.-J. Sohn, and G. Liu, 2007: How TRMM precipitation radar and microwave imager retrieved rain rates differ. Geophys. Res. Lett., 34, L24803, https://doi.org/10.1029/ 2007 GL032331.

—, S. Hristova-Veleva, G. Liu, M.-L. Ou, and G.-H. Ryu, 2015: Long-term comparison of collocated instantaneous rain retrievals from the TRMM Microwave Imager and Precipitation Radar over the ocean. J. Appl. Meteor. Climatol., 54, 867-879, https://doi.org/10.1175/JAMC-D-14-0235.1.

Shige, S., H. Sasaki, K. Okamoto, and T. Iguchi, 2006: Validation of rainfall estimates from the TRMM precipitation radar and microwave imager using a radiative transfer model: 1 . Comparison of the version-5 and -6 products. Geophys. Res. Lett., 33, L13803, https://doi.org/10.1029/2006GL026350.

_- T. Watanabe, H. Sasaki, T. Kubota, S. Kida, and K. Okamoto, 2008: Validation of western and eastern Pacific rainfall estimates from the TRMM PR using a radiative transfer model. J. Geophys. Res., 113, D15116, https://doi.org/ 10.1029/2007JD009002.

Silberstein, D. S., D. B. Wolff, D. A. Marks, D. Atlas, and J. L. Pippitt, 2008: Ground clutter as a monitor of radar stability at 
Kwajalein, RMI. J. Atmos. Oceanic Technol., 25, 2037-2045, https://doi.org/10.1175/2008JTECHA1063.1.

Steiner, M., R. A. Houze Jr., and S. E. Yuter, 1995: Climatological characterization of three-dimensional storm structure from operational radar and rain gauge data. J. Appl. Meteor., 34, 1978-2007, https://doi.org/10.1175/1520-0450(1995)034<1978: CCOTDS $>2.0 . \mathrm{CO} ; 2$.

Su, H., and J. H. Jiang, 2013: Tropical clouds and circulation changes during the 2006/07 and 2009/10 El Niños. J. Climate, 26, 399-413, https://doi.org/10.1175/JCLI-D-12-00152.1.

Trenberth, K. E., 1997: The definition of El Niño. Bull. Amer. Meteor. Soc., 78, 2771-2778, https://doi.org/10.1175/1520-0477 (1997)078<2771:TDOENO > 2.0.CO;2.

Wang, J.-J., R. F. Adler, and G. Gu, 2008: Tropical rainfall-surface temperature relations using TRMM precipitation data. J. Geophys. Res., 113, D18115, https://doi.org/10.1029/ 2007JD009540.

Wolff, D. B., and B. L. Fisher, 2008: Comparisons of instantaneous TRMM ground validation and satellite rain-rate estimates at different spatial scales. J. Appl. Meteor. Climatol., 47, 2215-2237, https://doi.org/10.1175/2008JAMC1875.1.
— , and - 2009: Assessing the relative performance of microwave-based satellite rain-rate retrievals using TRMM ground validation data. J. Appl. Meteor. Climatol., 48, 1069-1099, https://doi.org/10.1175/2008JAMC2127.1.

—, D. A. Marks, E. Amitai, D. S. Silberstein, B. L. Fisher, A. Tokay, J. Wang, and J. L. Pippitt, 2005: Ground validation for the Tropical Rainfall Measuring Mission (TRMM). J. Atmos. Oceanic Technol., 22, 365-380, https://doi.org/ 10.1175/JTECH1700.1.

$\mathrm{Xu}$, W., and S. A. Rutledge, 2015: Morphology, intensity, and rainfall production of MJO convection: Observations from DYNAMO shipborne radar and TRMM. J. Atmos. Sci., 72, 623-640, https://doi.org/10.1175/JAS-D-14-0130.1.

Yoneyama, K., C. Zhang, and C. N. Long, 2013: Tracking pulses of the Madden-Julian oscillation. Bull. Amer. Meteor. Soc., 94, 1871-1891, https://doi.org/10.1175/BAMS-D-12-00157.1.

Zuluaga, M. D., and R. A. Houze Jr., 2013: Evolution of the population of precipitating convective systems over the equatorial Indian Ocean in active phases of the Madden-Julian oscillation. J. Atmos. Sci., 70, 2713-2725, https://doi.org/10.1175/ JAS-D-12-0311.1. 